\title{
La necroeconomía de la generación de electricidad para la minería. El impacto comunitario del uso del petcoke en Tocopilla (Chile, 2000-2015) ${ }^{1}$
}

\author{
The necroeconomy of electricity generation for mining. The community impact of the use \\ of petcoke in Tocopilla (Chile, 2000-2015)
}

Damir Galaz-Mandakovic

Universidad de Tarapacá, Chile

RESUMEN Desde una metodología historiográfica y una hermenéutica antropológica, en este artículo se describe y analiza un proceso derivado de la gran minería del cobre y de la generación de energía eléctrica necesaria para desarrollarla en el primer lustro el siglo XXI. Dichos regímenes productivos, en el marco de la competitividad comercial, derivaron en una necroeconomía a través de la introducción del petcoke como combustible en las termoeléctricas. El petcoke estructuró una fuerte precarización socioambiental y forjó la producción de una subsidiariedad territorial y comunitaria; es decir, la población de Tocopilla tuvo que respirar, soportar y sufrir los efectos ambientales y corporales de las decisiones productivas, las cuales estaban amparadas por agentes del Estado subsumidos y por la debilidad en la regulación medioambiental. Hablar de necroeconomía es visibilizar una de las funciones adversas del capitalismo y sus agentes subalternos en la política, el cual produce una población superflua, que ya no es necesario "explotar" sino que gestionar: una manera de disponer de estos excedentes de población es exponerlos a todo tipo de peligros y riesgos. De ese modo, se jerarquiza la vulnerabilidad y la muerte y se construye la desechabilidad en algunos grupos sociales a través de violencia lenta o de estallidos densos sobre "subconjuntos" de humanidad clasificados en un nivel inferior. Así, los sujetos de derechos, devienen en sujetos de desechos,

1. Este artículo es producto del proyecto FONDECYT No 11180932. 
y también en sujetos de muerte. Es decir, personas que, por factores economicistas ajenos, y de pronto invisibles, dejaron de ser parte del mundo social y fueron excluidos de las normas que velan por la protección vital.

PALABRAS CLAVES Tocopilla; termoeléctricas; minería del cobre; petcoke; contaminación, necroeconomía.

ABSTRACT From a historiographic methodology and an anthropoloical hermeneutic, this article describes and analyzes a process derived from large-scale copper mining and the generation of electrical energy. necessary to develop it, in the first five years of the 21st century. This production regime, within the framework of commercial competitiveness, led to a necroeconomy through the introduction of petcoke, as fuel in thermoelectric plants, This fuel structured a strong socio-environmental precariousness and forged the production of a territorial and community subsidiarity. In other words, Tocopilla population had to breathe, endure, and suffer the environmental and bodily effects of productive decisions, which were protected by subsumed state agents and by weakness in environmental regulation. To speak of necroeconomics is to make one of the adverse functions of capitalism and its subordinate agents in politics visible, which produces a superfluous population, no longer necessary to "exploit" but rather manage - one way of getting these population surpluses is exposing them to all kinds of dangers and risks. In this way, vulnerability and death are hierarchized and disposability is built in some social groups through slow violence or dense outbreaks on "subsets" of humanity classified at a lower level. Thus, the subjects of rights, become subjects of waste, and also subjects of death; in other words, people who, due to foreign and suddenly invisible economic factors, ceased to be part of the social world and were excluded from the norms that ensure vital protection.

KEYWORDS Tocopilla; power plant; copper mining; petcoke; pollution; necroeconomy.

\section{Introducción}

La llegada del gas natural al Norte Grande de Chile durante el segundo lustro de la década de 1990, tuvo un impacto negativo en las generadoras eléctricas que usaban carbón y que energizaban la gran minería del cobre. El bajo precio del gas llegaba a producir hasta un $40 \%$ de energía más barata. Para las termoeléctricas a carbón era imposible competir con los precios del gas, esencialmente por las innovaciones que debían realizarse en temas de infraestructura. Esta situación impulsó a las genera- 
doras carboneras a ver en el petcoke ${ }^{2}$ un aliado preciso para poder competir en el mercado del Sistema Interconectado del Norte Grande (SING) (Gamboa y Huneeus, 2007). No obstante, la disminución de los envíos de gas desde Argentina a Chile desde el año 2004, propiciaron aún más la introducción del petcoke, adición de combustible que trajo aparejado un lóbrego proceso de alto impacto ambiental, generándose la sacrificialidad de Tocopilla, ciudad que durante el siglo XX fue conocida popularmente como La Capital de la Energía (Galaz-Mandakovic, 2017).

La sacrificialidad ambiental y sanitaria de Tocopilla la comprendemos desde una mirada territorial bajo un proceso de colonización minera que además de tener huellas económicas, tecnológicas, simbólicas y políticas, posee profundas huellas ecológicas. Porque colonizar la costa de Atacama para quemar combustibles y generar electricidad para las minas durante el siglo XX, significó funcionalizar el territorio en aras de un proyecto capitalista (de origen foráneo) alterando deliberadamente el ambiente socio-ecológico, trastornando las naturalezas y generando la comoditización de los recursos, no solo de lo extraído (agua y minerales), sino que también para depositar las miles de toneladas de cenizas resultantes de la combustión de carbón y petcoke, surgiendo verdaderas montañas de desechos que archivan y testimonializan una forma de colonización y metabolismo ${ }^{3}$ socioambiental, donde se adiciona el fuerte impacto en la población, la que finalmente pagó los costos y subvencionó con su biología el desarrollo de la minería del cobre hasta el tiempo presente, siendo la injusticia social un eje estructurante de la relación anómala entre economía, medio ambiente y los derechos humanos, "especificamente con quienes deben soportar las cargas de manera desproporcionada" (Infante, 2016, p. 144).

Develar históricamente la trama tocopillana es fundamental, porque significa dar muestra del proceso que ha llevado el capitalismo minero en su integridad en el Desierto de Atacama y no parcelado como lo ha hecho la historiografía y antropología

2. El petcoke, también aludido como "coque de petróleo", es un sólido carbonoso derivado de las unidades de coquización en una refinería de petróleo o de otros procesos de craqueo. Es producto de las sobras del proceso de refinado del petróleo, por lo cual contiene altas cantidades de azufre, níquel, cromo y vanadio. El coke originado de las fracciones más pesadas del petróleo, concentra las impurezas más densas, el contenido de esos componentes depende directamente de la calidad del petróleo procesado. Así, se puede obtener petcoke en el mercado internacional a bajos precios, con alto poder calorífico, pero con fuertes contenidos de azufre (Santos y Silva, 2008). La combustión de petcoke produce una significativa emisión de anhídrido sulfuroso y material particulado fino, conocido como PM1o (Particulate Matter). Son pequeñas partículas sólidas o líquidas de polvo, cenizas u hollín dispersas en la atmósfera, cuyo diámetro es menor que $10 \mu \mathrm{m}$ (1 micrómetro corresponde la milésima parte de 1 milímetro).

3. Según las consideraciones de Toledo (2013) el metabolismo social está constituido por los flujos de entrada, los flujos interiores y los flujos de salida, los cuales están cruzados por cinco fenómenos: 1) la apropiación, 2) la transformación, 3) la circulación, 4) el consumo y 5) la excreción. 
regional y nacional, que usualmente les ha dado la espalda a los densos fenómenos vividos en la costa del desierto y se ha fijado solamente en los "épicos" yacimientos cupríferos (los más grande del orbe) como si estos fuesen fenómenos insulares. En ese sentido, queremos caracterizar y visibilizar localizadamente las relaciones entre capitalismo, Estado, naturaleza y población en el caso de Tocopilla, ciudad que no aparece en los grandes relatos políticos, historiográficos, antropológicos, económicos ni en los diversos trabajos científicos.

Desde una metodología historiográfica y una hermenéutica antropológica, en ese artículo, a través de fuentes primarias obtenidas en archivos administrativos, archivos sanitarios locales y provinciales, además de fuentes hemerográficas, queremos dar muestra de un estudio territorial y de una historia contemporánea. Queremos plantear como hipótesis que, en el marco del capitalismo minero y la generación de energía eléctrica necesaria para desarrollarla, se practicó lo que podemos denominar como una necroeconomía (Mbembe, 2006) en un espacio periférico y satelital, tal como lo representa Tocopilla. Aquellos procesos de termogeneración de energía eléctrica, además de funcionalizar un territorio costero, dieron pie a una indolencia industrial con base al uso de combustibles altamente tóxicos, tales como el petcoke. Ese régimen de indolencia fue la derivación de una competencia comercial que tuvieron que enfrentar las termoeléctricas en los finales de la década de 1990, especialmente, con el ingreso del gas argentino. En ese sentido, como una consecuencia del mercado de los combustibles, se forjó una precarización socioambiental intensa, un nuevo régimen químico de la vida (Murphy, 2008), forzando la producción de una subsidiariedad territorial y comunitaria; es decir, una población que tuvo que respirar, soportar y sufrir los efectos ambientales y patológicos de las decisiones productivas, amparadas por un Estado subsumido, débil y anacrónico en su regulación medioambiental.

La sacrificialidad de Tocopilla devela las crisis y las negatividades del capitalismo minero en Atacama y su relación con el mercado mundial, evidenciándose aparatosa y dramáticamente las contradicciones y antagonismos de la producción, del extractivismo y el desinterés por las poblaciones locales que asumen la parte negativa para que la minería siga siendo vista como el "sueldo de Chile". Pero, para que exista ese "sueldo de Chile", han debido existir cuerpos y territorios subalternos y sacrificiales (Klein, 2015), construidos como tales en el marco de una necroeconomía. Siguiendo la huella de Achille Mbembe, hablar de necroeconomía ${ }^{4}$ es visibilizar una de las fun-

4. Vladimir Papava (2005) también usó el concepto de necroeconomía, no obstante, este lo usó en el contexto del desarme de la Unión Soviética, donde la llamada por él como "economías de mando", que serían las empresas estatales, en sus procesos de transición hacia el capitalismo durante la década de 1990, devinieron en empresas "muertas", que generaban déficit, con escasas posibilidades de competencia. En su oposición, estaban las empresas privadas competitivas y exitosas ante lademanda, a las que denominó como parte de la vita-economía. 
ciones aciagas del capitalismo, el cual produce una población superflua, la que ya no es necesario "explotar" sino que gestionar: "Una manera de disponer de estos excedentes de población es exponerlos a todo tipo de peligros y riesgos" (Fernández-Savater, 2016, p. 1). De esa manera, se jerarquiza la vulnerabilidad y la muerte y se construye la desechabilidad (Voyles, 2015) en algunos grupos sociales a través de una violencia lenta (Nixon, 2011) y densa sobre subconjuntos de humanidad clasificados en un nivel inferior (Mbembe, 2006). En el caso de Tocopilla, los sujetos de derechos, devinieron en sujetos de desechos, y también en sujetos de muerte. Es decir, personas que por factores economicistas alóctonos, y usualmente invisibles, dejaron de ser parte del mundo social y sus normas para proteger la vida. Es ahí el "exceso del capitalismo" (Costas, 2014) que les abrió un camino sin retorno y con densas huellas bio-antropológicas.

Estas áreas de sacrificio demuestran que el tema de la contaminación ambiental está íntimamente relacionado con las anacronías de las regulaciones ambientales y por los patrones de desigualdad social y asimetría económica. Por lo tanto, son las comunidades con los ingresos más bajos las que históricamente han debido soportar, asumir y contener los efectos negativos del crecimiento económico de la sociedad en su conjunto. El siglo XXI se inauguraba en Tocopilla con una realidad que estaba definida por alrededor de 23.986 habitantes (Censo, 2002), de los cuales 10.000 constituían su fuerza de trabajo. El nivel de pobreza era del 25,4\% en el año 2000, índice que superaba significativamente la media regional $(13,1 \%)$ y nacional $(21,7 \%)$, lo que determinaba una tasa de cesantía aproximada de 15\%, además de poseer en aquel periodo un 9,8\% de su población en situación de indigente, mientras que la Región poseía 2,9\% y el país, 5,6\% (Archivo Biblioteca Congreso Nacional (ABCN), Cámara de Diputados, Legislatura 342a, Ordinaria, sesión 9, 4 de julio de 2000, p. 60). Visibilizar un caso singular de Zona de Sacrificio, permite "identificar y clasificar un lugar con el propósito de cuestionar actividades productivas percibidas como destructivas" (Hormazabal, et al., 2019, p. 8).

\section{La ciudad de la energía}

El 18 de mayo de 1915 la familia Guggenheim de New York, a través de la empresa The Chile Exploration Company, inauguró en el desierto de Atacama la mina de cobre más grande del mundo: Chuquicamata. Para ello, hubo que implementar una poderosa termoeléctrica en el puerto de Tocopilla, distante a 140 kilómetros del yacimiento cuprífero.

La generación de energía eléctrica, vital para las maquinarias de gran escala y la aplicación del proceso de electrolisis en la refinación del cobre, estaría sustentada en la combustión de petróleo importado desde EE.UU., gracias a un acuerdo establecido entre los hermanos Guggenheim y The Union Oil Company of California (GalazMandakovic, 2018; 2019). 
Por efecto de los procesos de chilenización de los recursos naturales (Ley 16.425, 25 de enero de 1966) y de nacionalización (Ley 17.450, 16 de julio de 1971), la termoeléctrica estadounidense en Tocopilla pasó a propiedad del Estado de Chile a través de CODELCO. En ese nuevo escenario corporativo, la empresa introdujo en el año 1983 el carbón bituminoso y sub-bituminoso como principal combustible, lo cual implicó la inauguración de nuevos procesos operativos internos. Era uno de los efectos de la crisis del petróleo desarrollada en la década anterior que exigió un cambio de combustible. El ingreso del carbón como combustible fue vital para sostener la minería del cobre. Las Unidades a carbón fueron la Unidad No 12 , (85,3 MW), No 13, (85,5 MW), No $14(136,4 \mathrm{MW})$ y la Unidad No $15(132,4 \mathrm{MW})$ (GalazMandakovic, 2017).

En 1996, la termoeléctrica de CODELCO fue privatizada y se transformó en Electroandina S.A., perteneciente a Tractebel, Iberdrola y Enagás (Bélgica, España y Chile). Al mismo tiempo en que se privatizaba la termoeléctrica de CODELCO, se abrió la puerta para la instalación de una termoeléctrica vecina, llamada Norgener, también destinada a electrificar la gran minería del cobre y al Sistema Interconectado del Norte Grande (SING). Aquella empresa había sido constituida el 9 de agosto de 1993 y era una filial de CHILGENER, pero su denominación corporativa era Nueva Tocopilla (NORGENER). Esta empresa instaló dos Unidades de generación a carbón que tenían una potencia de $277 \mathrm{MW}$, la que fue inaugurada en Tocopilla en el año 1995 por el presidente Eduardo Frei Ruiz-Tagle. De esa forma el SING era alimentado en un 56\% por Electroandina, $12 \%$ de Norgener, 25\% de EDELNOR y con un $8 \%$ por Celta (Moguillansky, 1997). Es decir, desde Tocopilla se alimentaba con un $68 \%$ de aquellos 1.120 megawatt.

En el año 1995, los presidentes de Chile y Argentina, Eduardo Frei y Carlos Menen, respectivamente, firmaron el Protocolo de Interconexión Gasífera, siendo la empresa Repsol-YPF y Mobil las que suministrarían a Chile. De ese modo, las empresas carboneras del norte, comenzaron a perder competitividad ante los bajos precios del gas. Desde el año 2000 al 2004, la situación fue caótica, por efecto de la decisión del gobierno de Argentina de restringir el suministro de gas hacia Chile (El Mercurio, 2 de abril de 2004).

\section{La combustión del petcoke}

El ingreso del petcoke en los finales de la década de 1990 fue abiertamente ilegal y casi simultáneo al ingreso del gas argentino. Así quedó establecido en la discusión parlamentaria del 13 de julio del año 2000 (Sesión ordinaria 16 a). En la ocasión el diputado Leopoldo Sánchez denunció que se había contabilizado el ingreso de más de un millón de toneladas de modo subrepticio por parte de algunas termoeléctricas. Si bien existía una serie de vacíos legales que regularan este tipo de ingresos, la ilegalidad 
de la entrada del petcoke radicó en que era declarado como "producto comercial" en los registros aduaneros de importación. Ante dicha falta, Norgener fue multada con 500 Unidades Tributarias Mensuales en el primer semestre del año 2000, considerado el alto componente tóxico del producto (Archivo Gobernación Provincial de Tocopilla (AGPT), Resolución № 1632 del Servicio de Salud de Antofagasta, 19 de abril de 1999).

El 5 de agosto de 1999, en el diario La Prensa de Tocopilla, Luis Knaak, jefe de planta de Norgener, afirmaba que, el petcoke, "en apariencia es igual al carbón. Hace treinta años que es utilizado como combustible en países de alta cultura ambiental (...) no produce daño alguno si es manejado con responsabilidad". Por su parte, el intendente de Antofagasta de la época, Cesar Castillo Lilayú, indicó en una reunión pública realizada en la gobernación de Tocopilla que, "si el petcoke que pretenden usar no contiene níquel, vanadio ni azufre entonces, lo aprobamos inmediatamente (...) no se trata de satanizar ni angelicalizar" (La Prensa de Tocopilla, 1 de septiembre de 1999).

El 17 de septiembre de 1999, el Mercurio de Antofagasta tituló: "Tocopilla está protegida", reproduciendo las palabras de Cristian Ullrich (experto en gestión ambiental de Electroandina) quien afirmó que, "la ciudad puede estar segura, que permanentemente son cautelados sus intereses, protegiendo la vida de la población y ayudando a conservar las áreas verdes" (El Mercurio de Antofagasta, 17 de septiembre de 1999) (Figura 1).

En la discusión parlamentaria sobre el uso del combustible, el diputado por la zona de Tocopilla, Waldo Mora Longa, señaló: "Lo lógico sería permitir el uso del petcoke y obligar al Gobierno a que (...) realice los estudios serios y responsables, para determinar si su uso es factible y si es dañino para la población. Todos los estudios que han llegado del extranjero no demuestran con claridad que perjudica a la población" (ABCN, Cámara de Diputados. Sesión Ordinaria No 18. Legislatura Ordinaria № 342, 19 de julio de 2000, p. 44). Claramente, la opinión del diputado soslayaba tendenciosamente una amplia y antigua gama de literatura científica que certificaba los dañinos efectos de aquel combustible, como así también los diversos reportajes de diarios y revistas que citaban aquellos estudios. 


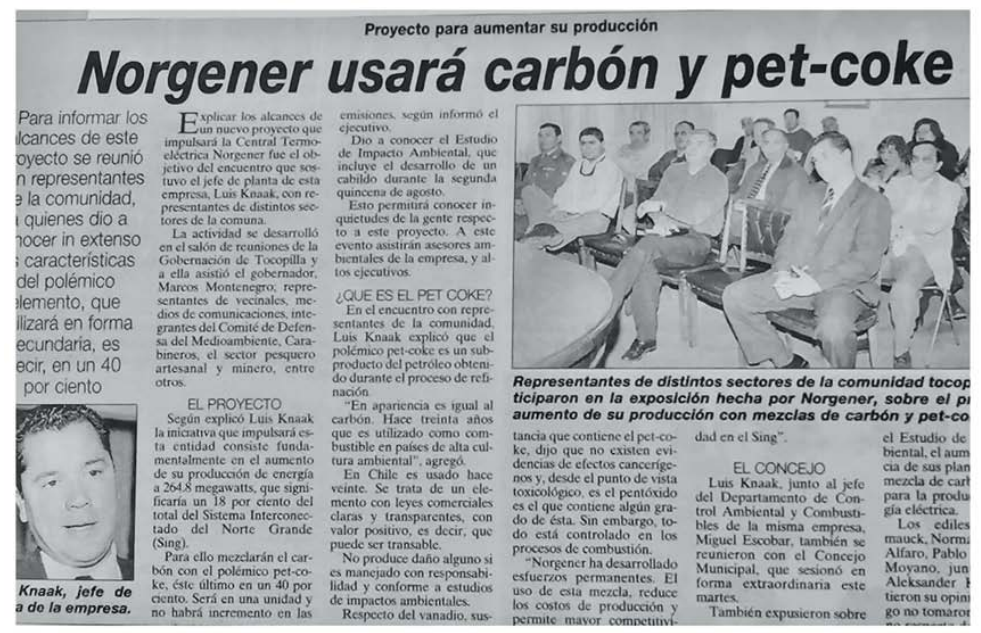

Charla "Ecología y medioambiente" fue ofrecida por Electroandina

\section{Tocopilla está protegida}

TOCOPILLA.- Ante una considerable asistencia, el experto en gestión ambiental de Electroandina, Cristion UUlich, ofrecio la charla "Ecología y Medioam-
oriental de Electroandina, Cristian Ulinch, biente", a la que asistio el gobemador Marcos Montenegro y el alcalde Aleksander Kurtovic, entre otras personalidades.

La exposición permití comprobar la importancia del tema, confirmando que que regulan la materia y que -a la vez- la comunidad tocopillana puede estar segura que permanentemente son cautelados sus que permanentemente son cautelados sus
intereses, protegiendo la vida de la población y ayudando a conservar las áreas verdes.

La charla tuvo lugar en el salón de actos de la municipalidad y se prolongo por casi tres horas. Luego de la exposición del profesional invitado, también se refirí a Medioambiente, ingeniero Andrés Tornquist.
Parte del público formuló diversas pre- la mejor forma posible. "Y esto comienza guntas, que fueron respondidas por los ex- en lo que se denomina "protección territopositores, lo cual permitio aclaner sus du-

Al inicio de la charla, el gerente de Operaciones de Electroandina, Víctor Núñez, expresó que el objetivo de ella era proporcionar a la comunidad conceptos y definiciones que rigen el control ambiental y das acerca del tema.

La conferencia del especialista principal consideró elementos generales de ecología, los componentes físicos, biológicos $y$ antropologicos del ambiente $y$ la intervención del ser humano como partícipe en el cambio permanente que sufre el medio-

Más adelante, Cristian Ullrich precisó que pese a las diversas amenazas que se ciemen sobre el ecosistema, existe el conque trata de manejar el tema ambiental en rial", que cobra importancia al darnos cuenta que para poder vivir en un lugar de. terminado, necesitamos protegerlo y conservarlo. Y cuando uno se acoge en determinado lugar, tenemos derechos y obligaciones sobre el mismo, ya sea el hogar, la escuela, la ciudad y el país".

En la segunda parte de la conferencia, Ullich describió los sistemas globales de monitoreo ambiental, pasando luego a exponer Andrés Tomquist, quien describió los diversos monitoreos ambientales efectuados en los últimos años, aportando antecedentes respecto a las estaciones respectivas, cuya ubicación ha sido determinada por la autoridad de salud, a la que se entregan períbdicamente los resultados.

La conferencia-taller constituye el inicio de una seric de acciones de protección y control del medioambiente en Tocopilla.

Figura 1. Cobertura de la prensa sobre el proceso de integración del petcoke en los procesos de generación de energía eléctrica en 1999, reportes donde es evidente la desinformación y la difusión de falacias científicas. Recorte superior: diario La Prensa de Tocopilla (5 de agosto de 1999). Recorte inferior: diario El Mercurio de Antofagasta (17 de septiembre de 1999). Archivo del autor.

Fue así que en el segundo semestre del año 2000 la empresa Norgener fue autorizada para quemar aquel combustible (El Mercurio, 26 de octubre de 2000), porque, supuestamente, se trataba de "plantas bastante nuevas y que son capaces de combustionar el petcoke, pero, para cumplir con la normativa ambiental, debe ser mezclado con carbón natural" (ABCN, Cámara de Diputados, Humberto Soto, Gerente General de Norgener S. A, sesión No 9, 4 de junio de 2000, p. 129). 
El diario El Mercurio, en su edición del 26 de septiembre de 2001, noticiaba que CONAMA había autorizado el uso el petcoke en dos termoeléctricas del norte de Chile gracias a que había acogido los estudios de impacto ambiental presentados por Norgener en Tocopilla y por la Central térmica de Guacolda en Huasco, esto ocurría "pese a que numerosos estudios científicos en el extranjero han postulado que los contaminantes que el petcoke emite tienen efectos cancerígenos en la población que se expone a él" (El Mercurio, 26 de septiembre de 2001).

Según el citado diario, el Ministro Secretario General de la Presidencia, Eduardo Dockendorff, había indicado que se acogió unánimemente los informes presentados por considerarlos como "satisfactorios", porque aparentemente promovían un acuerdo que terminaba con una polémica que había sido iniciada en el periodo presidencial de Eduardo Frei Ruiz-Tagle, la cual estaba centrada en el uso de este tipo de combustibles al saber que ya se conocían una serie de informes científicos que comprobaban la alta toxicidad para el ambiente esencialmente por los efectos cancerígenos. El Ministro Dockendorff señaló que se había introducido un criterio y una norma que establecía "grandes exigencias" al cumplimiento tecnológico de empresas para proteger y asegurar la salud de la población, adicionando que se había fijado unas condiciones para la importación de este producto como así también requerimientos de funcionamiento de las entidades que lo utilizaran, basándose en las normas de países desarrollados que ya habían autorizado su uso, no obstante, no indicó qué países utilizaban petcoke. Lo que no dijo el personero de gobierno es que la autorización estatal en el uso del petcoke superaba en diez veces las exigencias que habían planteado como necesarias las organizaciones ecologistas de Chile y la denominada Bancada Verde del parlamento chileno (El Mercurio, 8 de julio de 2000), quienes postulaban que este contaminante no podía superar las 50 partes por millón. Otra personera "satisfecha" con la permisión fue la directora de la Comisión Nacional del Medio Ambiente, Adriana Hoffman, quien indicó al diario El Mercurio que la anuencia "está de acuerdo a todas las normas técnicas que hemos llevado a adelante con la CONAMA. Sobre todo, que se han hecho estudios y mediciones de las emisiones reales" (El Mercurio, 26 de septiembre de 2001).

Una vez que se dio la autorización, el trámite pasó a manos de Contraloría de la República, organismo que validó rápidamente el proceso.

Cuando la noticia sobre la permisión llegó a Tocopilla, surgió el rechazo de los grupos ambientalistas. El Diario de Cooperativa tituló: "El Comité Ambiental de Tocopilla se mostró defraudado de la justicia tras la decisión de la Tercera Sala de la Corte Suprema que autorizó la utilización de combinados de petcoke (derivado del petróleo) y carbón en procesos industriales" (10 de julio de 2002).

Cabe indicar que una vez que se supo el dictamen de septiembre del año 2001, los pobladores tocopillanos habían presentado tres Recursos de Protección para evitar el 
uso de mezclas de carbón bituminoso y petcoke, pero la respuesta de la Corte Suprema indicó que las emisiones de níquel y vanadio originadas por el uso de petcoke eran menores a las normas establecidas ${ }^{5}$. Dentro de la resolución de la Corte Suprema, había una extraña e indolente determinación: “...si bien la Constitución garantiza el derecho a vivir en un ambiente limpio, no se refiere a un lugar exento de toda contaminación" (Diario de Cooperativa, 10 de julio de 2002).

Al poco tiempo, la termoeléctrica de Electroandina, que quintuplicaba en combustión a Norgener, se sumaría como consumidor de este derivado del petróleo, significando aumentar fuertemente la vulnerabilidad ambiental y sanitaria de la comunidad.

El Intendente de Antofagasta, el abogado Jorge Molina Cárcamo, firmó el 5 de abril de 2002 una resolución que autorizaba el proyecto de Electroandina, resolución que desoyó el clamor popular, las observaciones y cuestionamientos de las organizaciones ambientalistas, entre ellas el Comité de Defensa del Medio Ambiente de Tocopilla (CODEMAT), además de las recomendaciones de académicos y expertos, asimismo, de los reclamos de una serie de vecinos y personalidades que habían asistido a la sesiones de COREMA en Antofagasta. La resolución indicaba: "Certificar que el proyecto 'Uso de mezclas de carbón con coque de petróleo como combustible en Central termoeléctrica de Tocopilla' presentado por Electroandina S.A., cumple con todos los requisitos ambientales aplicables, con la normativa de carácter ambiental, incluidos los requisitos de carácter ambiental contenidos en el permiso sectorial correspondiente al Artículo 94 del D.S. No30/1997 (...) se han establecido medidas de mitigación, compensación y reparación apropiada" (AGPT, Resolución exenta ํo77, Intendencia de Antofagasta, J. Molina, 5 de abril 2002).

Sin embargo, la empresa autorizada quiso eludir una serie de conductos regulares sanitarios y decidió usar petcoke durante el año 2003 sin considerar las diversas medidas de mitigación que se habían establecido.

El diario La Prensa (29 de enero de 2004) indicaba la sorpresa y desautorización por parte del Intendente Jorge Molina Cárcamo hacia Electroandina, quien exponía como razón que la empresa generadora había solamente "informado" que comenzaría a usar petcoke. En ese contexto, el Intendente curiosamente indicó que dicha empresa no estaba facultada para ocupar aquel combustible que era tan cuestionado por la comunidad. "La empresa no estará autorizada, mientras no se den cumplimientos

5. El mayor efecto del aumento de material particulado por uso de petcoke se produce en las termoeléctricas que usan filtros electrostáticos. Katz indica que la contaminación secundaria, la emisión de $\mathrm{SO} 2$, se transforma en $\mathrm{SO} 3$ (óxido de azufre) y a su vez éste en $\mathrm{SO} 4$ (sulfato). En presencia de vapor, el SO4 da origen a la formación de $\mathrm{H} 2 \mathrm{SO} 4$ (ácido sulfúrico), que al condensar produce la denominada lluvia ácida. Este proceso se acelera en la medida que encuentra un catalizador, que en este caso es el pentóxido de vanadio (V2 O5) (Katz, 2001, pp. 28-29). 
exactos a todas las condiciones que fueron impuestas por la Comisión Regional del Medio Ambiente" (La Prensa, 29 de enero 2004).

Estas acciones irresponsables y fuera del marco legal por parte de la termoeléctrica Electroandina, dejaban en claro la evasión de una serie de normativas jurídicas sobre la protección del medio ambiente, soslayando a las instituciones estatales y desconsiderando a la población, quienes tendrían que pagar los costos sanitarios asociados al uso de este deletéreo combustible.

En ese escenario, a través de los periódicos, el intendente Jorge Molina Cárcamo indicó que el visado dependería de la instalación de los respectivos mecanismos de control de poluciones y emanaciones de material particulado, exigidos esencialmente para este tipo de inflamable: "La gobernación y la municipalidad tendrán que comunicar que los computadores destinados a informar a la comunidad están instalados, mientras que el Servicio de Salud deberá dar cuenta que la información sobre los niveles de poluciones está llegando en línea desde Tocopilla hasta Antofagasta", mencionó a La Prensa (29 de enero 2004) ${ }^{6}$.

En marzo del año 2004, el Gobernador de la Provincia de Tocopilla, Jorge Peralta Villagra, indicaba que las estaciones de monitoreo funcionaban con normalidad y que contaban con la autorización de la COREMA y el Servicio de Salud de Antofagasta (La Prensa, 11 de marzo 2004). Estas estaciones fueron instaladas en distintos sectores de la ciudad, pero cabe indicar que los encargados de la mantención y de los informes serían los trabajadores de la misma empresa termoeléctrica. Esta situación le restó total y absolutamente neutralidad y transparencia al proceso de revisión de las emisiones de material particulado.

El 6 de abril de 2004, el diario La Tercera, informaba de la aprobación definitiva a Electroandina para usar petcoke en sus procesos de producción de electricidad, para ello, tuvo que revisar el Estudio de Impacto Ambiental presentado por la misma empresa. De esta forma, Electroandina se convirtió en la tercera termoeléctrica en

6. Cabe mencionar que la resistencia de la comunidad se expresó en varios lugares y encuentros entre autoridades, empresa y comunidad. Una de ellas fue la accidentada y conflictiva reunión en un salón municipal donde la empresa expuso su propuesta. En dicha reunión estaban presente los representantes del Servicio de Salud de Antofagasta, los integrantes del Consejo Regional del Medio Ambiente y pobladores. Además, la empresa termoeléctrica Electroandina envió a trabajadores, especialmente a los integrantes del Sindicato de Trabajadores, para defender a la empresa y explicar que la combustión de petcoke significaría "más trabajo para Tocopilla". En dicha reunión, los representantes de la empresa no supieron responder a una serie de preguntas y cuestionamientos realizados por los vecinos, los cuales estaban asesorados por el académico Jaime Parada, Doctor en Ingeniería, quien además era integrante de la Corporación para el Desarrollo Sustentable, entidad que apoyaba las acciones que llevaba a cabo el Comité de Defensa del Medio Ambiente de Tocopilla. "En la reunión varios de los asistentes mostraron su molestia por la aprobación que entregaron los organismos de control ambiental, ya que el puerto presenta, según ellos, claros signos de una gran contaminación" (La Prensa, 22 de enero 2004). 
Chile en usar dicho combustible, después de su vecina y coterránea Nueva Tocopilla de Norgener y después de la termoeléctrica Guacolda de Huasco, también perteneciente a Norgener.

Cuatro meses después, en agosto, la Comisión Regional del Medio Ambiente, resolvió sancionar a la empresa Electroandina por "incumplimientos ambientales en sus proyectos de desarrollo". El diario El Mercurio de Antofagasta (26 de agosto 2004) agregaba que la generadora registró una excedencia en la norma de calidad del aire de anhídrido sulfúrico (SO2) en la estación de monitoreo instalada en la Escuela Gabriela Mistral de Tocopilla, alcanzando emisiones de 400 microgramos por metro cúbico como promedio día, a saber que la norma solo autorizaba 365 microgramos. Fue entonces que se aplicó una multa, la cual fue considerada como misérrima e insignificante para un consorcio internacional del tamaño de Electroandina: la multa fue de 400 UTM, alrededor de 12 millones de pesos de la época. No quepa duda que resultaba mucho más rentable pagar la multa, los sustanciosos resultados económicos que significaba la introducción del petcoke, al saber que se estaba cuajando una realidad compleja en la salud de la población tocopillana.

De esa manera, ambas empresas produjeron una reducción de costos de alrededor de $35 \%$ en la generación de energía eléctrica, "ese costo de 35 \% llega a alrededor de 9,4 dólares por megawatts hora, que es el costo variable tomado en cuenta la legislación chilena para despachar una Unidad (de generación) y satisfacer la demanda eléctrica" (ABCN, Cámara de Diputados, Luis Hormazábal, Gerente de Inversiones de la empresa Electroandina S. A., sesión No9, 4 de junio de 2000, p. 129).

Fue así que, en ese marco economicista, la introducción del petcoke era "atractiva", porque dicho producto era de sorprendente bajo precio y auxiliaba el aumento de la productividad; por ejemplo, en los finales de la década de 1990 su precio fluctuaba entre los US\$ 2 y US\$14 la tonelada (Andrews y Lattanzio, 2013), "el precio internacional del petcoke depende principalmente de su contenido de azufre. Cuando el contenido de azufre es menor, el precio es mayor" (ABCN, Diputado L. Sánchez, Sesión ordinaria $16^{\text {a }}, 13$ de julio de 2000: 33).

El mismo diputado Leopoldo Sánchez, Informante de la Comisión de Recursos Naturales, Bienes Nacionales y Medio Ambiente, indicó: "el petcoke como combustible (...) ha sido adquirido al precio simbólico -entre otros antecedentes que tenemos- de un dólar la tonelada." (ABCN, Diputado L. Sánchez, Sesión ordinaria 16a 13 de julio de 2000: 33). El entonces diputado Alejandro Navarro había indicado en el año 2000: "nada en el mundo que cueste un dólar la tonelada, como este elemento, no tiene una doble intencionalidad oculta" (ElMercurio, 8 de julio de 2000). Los componentes como el arsénico, cadmio y cromo, son los que reducen su valor en el mercado internacional dándose la paradoja que los países generadores del residuo no lo empleen (Andrews y Lattanzio, 2013). 
Una vez que el petcoke era descargado de los barcos, las toneladas del combustible eran depositadas a la intemperie en la punta de la Península de Algodonales de Tocopilla, que por la acción del viento que proviene desde el suroeste, las partículas del combustible fueron trasladadas desde las canchas de acopio hacia la ciudad, considerando además la caída del combustible al fondo marino de la bahía.

Desde entonces, la combustión del petcoke, sólido poroso oscuro que contiene altas cantidades de azufre y esencialmente níquel, cromo y vanadio, generó la emisión significativa de anhídrido sulfuroso y material particulado fino, conocido como PM10, partículas formadas principalmente por compuestos inorgánicos como silicatos y aluminatos, metales pesados y material orgánico asociado a partículas de carbono, esencialmente hollín. La población fue expuesta a respirar aquellos corpúsculos de metales pesados, como el vanadio, el cual es un severo irritante de las membranas mucosas de los ojos, también de la nariz, irritador de la garganta y afectador del aparato respiratorio y a la piel. Se adicionaba el níquel, un alto promotor de cáncer al pulmón y en los senos paranasales (Katz, 2001), causando seguidas irritaciones a la piel y en las vías respiratorias. Del mismo modo, el cromo, considerado un metal pesado cancerígeno, el cual es emitido a la atmósfera y precipita con la humedad, depositando en las aguas del mar y en el suelo, ingresando al cuerpo de las personas a través del aire y también por la comida. La OMS considera al cromo hexavalente como elemento cancerígeno (Kazt, 2001).

Fue entonces que los flujos navieros con altos volúmenes de petcoke devinieron en una cotidianeidad, por ejemplo, en mayo del año 2006 el semanario El Polémico (Tocopilla) noticiaba: " $\mathrm{Barco}$ con 40 mil toneladas de petcoke llegó a Tocopilla?" (24 de mayo 2006), el barco llevaba por nombre Özge Aksoy.

La anuencia que albergó el uso del petcoke representó una peligrosa regresión que evidencia de manera dramática la baja relevancia que poseían los temas medioambientales para los gobiernos de la postdictadura, siendo muchas veces efectivas las verdaderas campañas del terror en cuanto al surgimiento de cesantía y déficit energético si acaso aumentaban las regulaciones. Este proceso estuvo basado "en una necesidad pretendidamente insoslayable por parte de la economía" (MontoyaAguilar, 2009, p. 280). El diario El Mercurio comentó sobre el gobierno de Ricardo Lagos que "está atrapado entre aceptar inversiones y hacer respetar la ley." (8 de julio de 2000). 


\section{Los depósitos de cenizas del petcoke}

Una vez que comenzó el uso del combustible contaminante, no se reguló el depósito de cenizas a saber que el Servicio de Salud de Antofagasta indicó que el cenizal existente en Tocopilla estaba destinado, en primera instancia (desde 1983), a las cenizas de carbón bituminoso y no a las de petcoke al saber de su alta toxicidad ${ }^{7}$. De igual modo, las cenizas fueron depositadas en el límite del radio urbano del puerto (a 7 kilómetros de las termoeléctricas, y a 1,5 kilómetros del último sector poblado). Fue así que se inició otro tipo de afectación comunitaria ${ }^{8}$.

Un factor perjudicial para la población que significativamente expande la contaminación de estos denominados "pasivos" es la constante presencia de vientos en el sector norte de Tocopilla. La suspensión de partículas contaminantes propagadas en el aire proveniente de los cerros de cenizas, afectaron de forma directa a la calidad de vida de los barrios tocopillanos (Galaz-Mandakovic, 2018), a saber, que es una contaminación en pequeñas partículas que es casi invisible cuando está en el aire.

La cercanía con el mar de estos acopios constituyó otra gran vulnerabilidad, porque el níquel y vanadio, como cualquier otro metal pesado, al entrar en contacto con el agua en cualquiera de sus manifestaciones (humedad ambiental, agua añadida a los depósitos de cenizas, agua presente en el rocío costero o camanchaca) infiltra a la dinámica de los ciclos biogeoquímicos correspondientes, lo que significa que serán transformados, transportados, redistribuidos y bioacumulados con los señalados efectos colaterales ecotoxicológicos que afectan desde los microorganismos hasta los humanos (ABCN, Cámara de Diputados, $17^{\circ}$ Sesión Ordinaria, en la 363a Legislatura, Comisión Especial Investigadora de la Actuación de los Organismos Públicos encar-

7. Los efectos tóxicos de la exposición a níquel, regularmente involucran a los riñones, con algunas evidencias de daño al desarrollo y aparatos reproductivos. La exposición por inhalación puede causar efectos tóxicos en el tracto respiratorio y sistema inmune. La dosis letal por inhalación para animales y personas varía entre $0,97 \mathrm{mg} \mathrm{Ni} / \mathrm{m} 3$ hasta $15 \mathrm{mg} \mathrm{Ni} / \mathrm{m} 3$ (Vidal, 2005). Los órganos vulnerables son los pulmones y el tracto respiratorio superior por la exposición por inhalación y los riñones ante una exposición o inhalación oral (Agency for Toxic Substances and Disease Registry [ATSDR], 2003). El níquel es un alto promotor de cáncer al pulmón y en los senos paranasales (Katz, 2001), causando seguidas irritaciones a la piel y en las vías respiratorias. Por su parte, el vanadio contenido en las cenizas posee una toxicidad que depende de su estado de oxidación y de su solubilidad, por ejemplo el pentóxido de vanadio V2O5 ha sido informado como cinco veces más tóxico que el trióxido de vanadio. Los compuestos de vanadio son suavemente absorbidos a través del tracto gastrointestinal, pero mayormente absorbidos por los pulmones (Vidal, 2005). Una vez que el vanadio ingresa al cuerpo humano, se distribuye principalmente en los huesos, riñones y también en el hígado.

8. En poblaciones expuestas en otros países, se ha evidenciado excesos de bronquitis, bronconeumonía, decoloración en la lengua, actividad irritante en la piel y en los ojos (ATSDR, 2003). El vanadio es también un severo irritante de las membranas mucosas de los ojos, también de la nariz, irrita la garganta y afecta al aparato respiratorio, incluyendo daños en la piel. 
gados de la Protección de la Salud y el Medio Ambiente en Antofagasta, 2 de octubre de 2015) (Figuras 2 y 3).

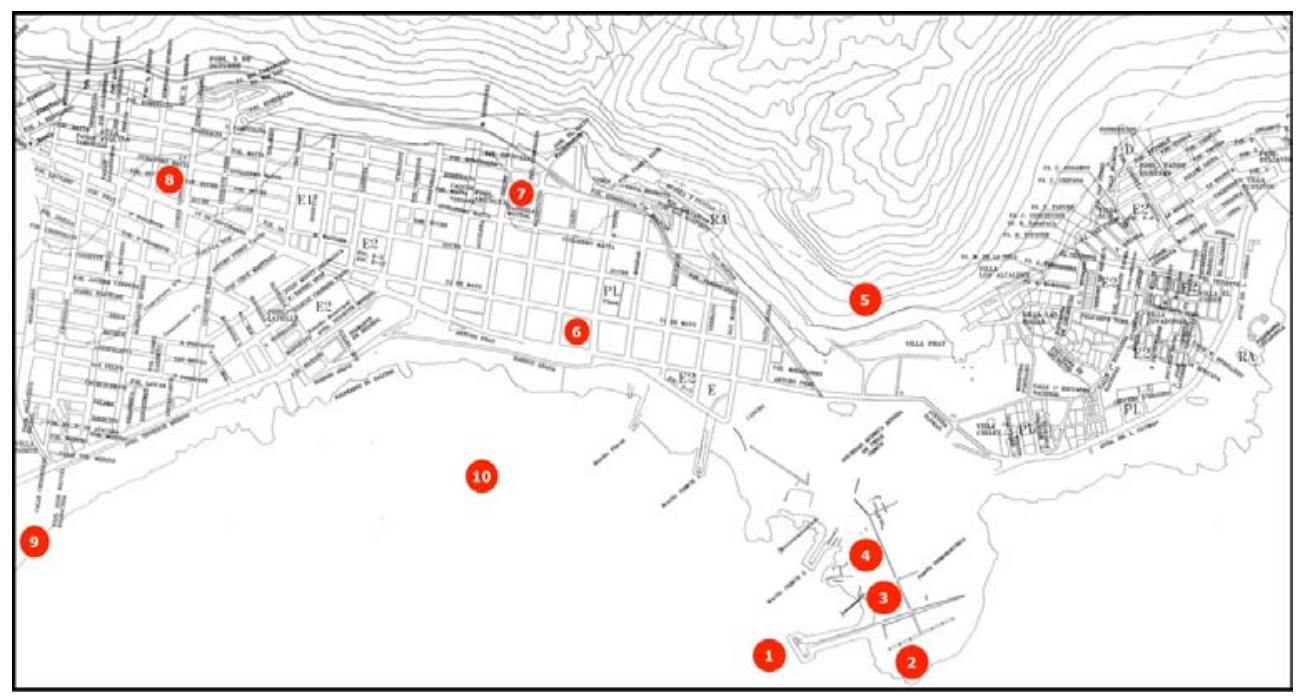

Figura 2. La bahía de Tocopilla y el contexto territorial de la generación de energía eléctrica 1) Muelles de descarga de carbón y petcoke. 2) Cancha de acopio de carbón y petcoke. 3) Termoeléctrica de Electroandina (hoy ENGIE). 4) Termoeléctrica de Norgener. 5) Cordillera de la Costa. 6) Estación de Monitoreo en Gobernación Provincial. 7) Estación de Monitoreo en Escuela Gabriel Mistral. 8) Estación de Monitoreo en Escuela Bernardo O’Higgins. 9) Acopio de cenizas de carbón y petcoke. 10) Bahía de Algodonales de Tocopilla.

Fuente: Elaboración propia. 

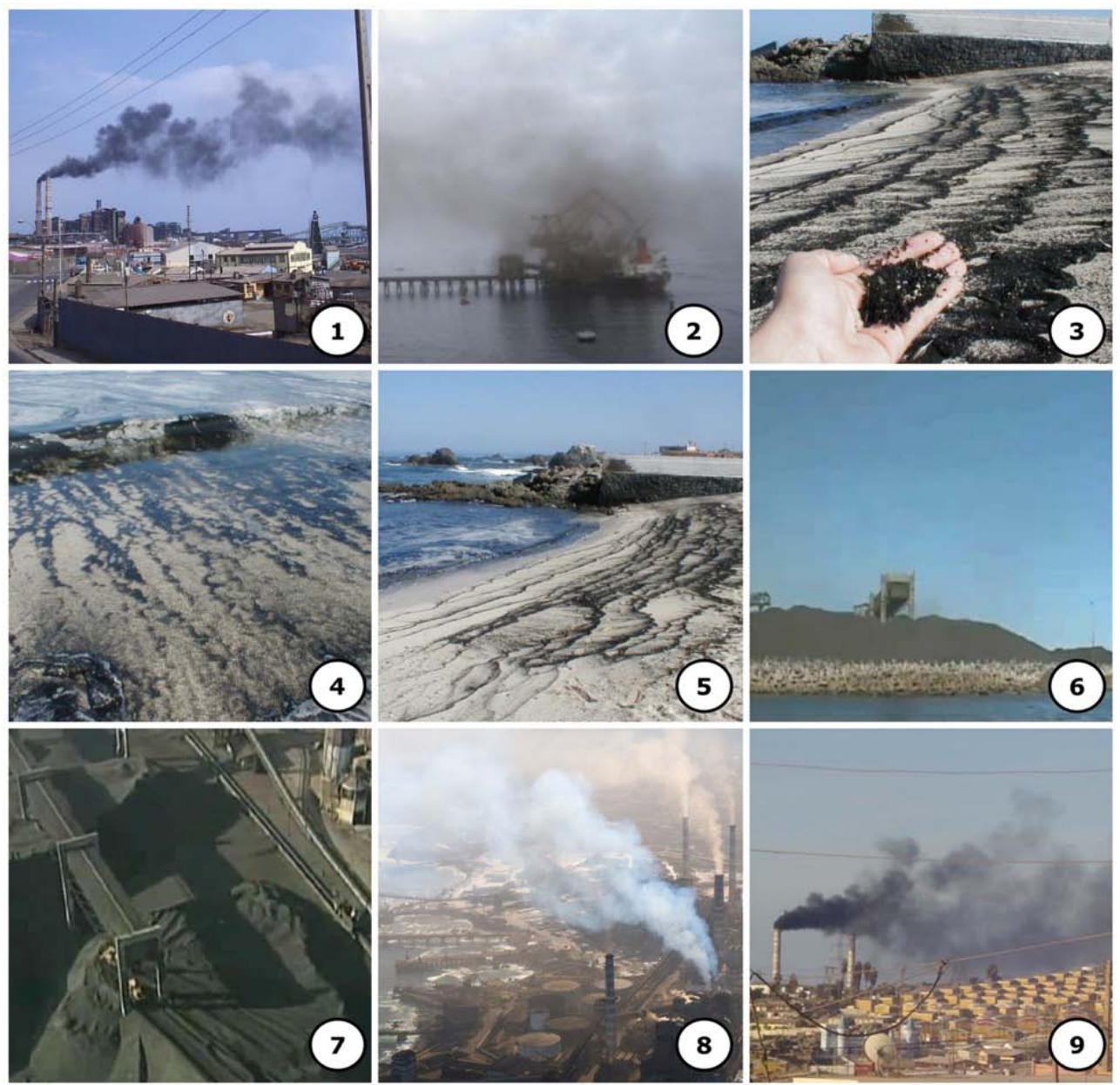

Figura 3. Distintas escenas derivadas de la generación de energía eléctrica en Tocopilla. 1) Humaredas emitidas por Norgener en época de combustión de petcoke. 2) Descontrol en la descarga de petcoke en los muelles de Electroandina (17 de noviembre de 2004). 3) Contaminación de petcoke en la playa La Hostería (1 km al sur de las termoeléctricas). 4) Combustible de termoeléctrica diseminado Playa La Hostería (21 de marzo de 2005). 5) Polución en Playa La Hostería (22 de marzo 2005). 6) Acopio de toneladas de petcoke a escasos metros del mar sin ningún tipo de mitigación. 7) Vista aérea del acopio de petcoke a la intemperie en el año 2006 (cancha de Electroandina). 8) Emanación de gases y material particulado desde las Platas de Norgener y Electroandina (8 de mayo 2008). 9) Contaminación de Norgener sobre la población del sector sur de la ciudad. Archivos del autor.

Fuente: elaboración propia. 


\section{Diagnóstico ambiental y la declaración de Zona Saturada}

Ante las presiones comunitarias por el aumento evidente de enfermos, el ennegrecimiento indudable de la ciudad gracias al hollín y ante la visibilización mediática de la realidad ambiental que había sido mutado sustancialmente, el Gobierno Regional de Antofagasta encomendó a la Dirección de Investigaciones Científicas y Tecnológicas de la Universidad Católica de Chile (DICTUC), la realización de un estudio para diagnosticar la realidad ambiental en Tocopilla durante el año 2005.

Un año después, en los resultados entregados por DICTUC, se apreciaba que se emitían diariamente sobre el puerto de Tocopilla considerables toneladas de contaminantes, tales como MP10, SO2 y NOx. (Figura 4).

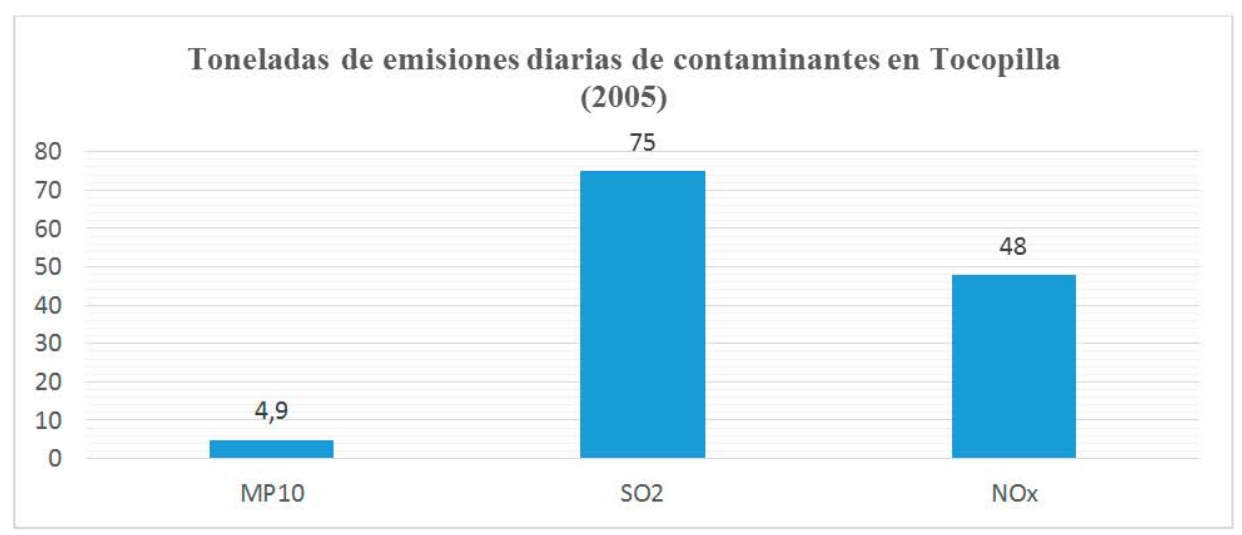

Figura 4. Cantidad de contaminantes (en toneladas) emitidos en Tocopilla durante el año 2005. Fuente: Archivo Gobernación de Tocopilla, Informe DICTUC (2006). Fuente: elaboración propia.

Examinando los resultados de investigación obtenidos por DICTUC (2006), podemos apreciar (Figura 5) el inventario de emisiones según su fuente, evidenciándose el aporte mayoritario de las termoeléctricas a las emanaciones de MP10, así también las emisiones de los principales precursores de material particulado secundario, tales como el dióxido de azufre (SO2), óxidos de nitrógeno (NOx) y monóxido de carbono $(\mathrm{CO})^{9}$, donde la empresa Electroandina (hoy llamada ENGIE) se visibilizaba como la empresa mayormente contaminante por quemar una mayor cantidad de petcoke.

9. Para la obtención de estos datos que hemos expuesto, la consultora instaló centrales de monitoreo del aire en cuatro lugares de Tocopilla. Centrales que tuvieron que examinar la proliferación de MP10 fino y grueso. Dichos análisis del aire tocopillano fueron realizados durante cinco semanas en el año 2005, las cuales fueron mencionadas como: Sitio 1, Escuela E -10; Sitio 2, Escuela Gabriela Mistral; Sitio 3, Gobernación Provincial y Sitio 4, balneario Punta Blanca (10 kilómetros al sur de Tocopilla). 


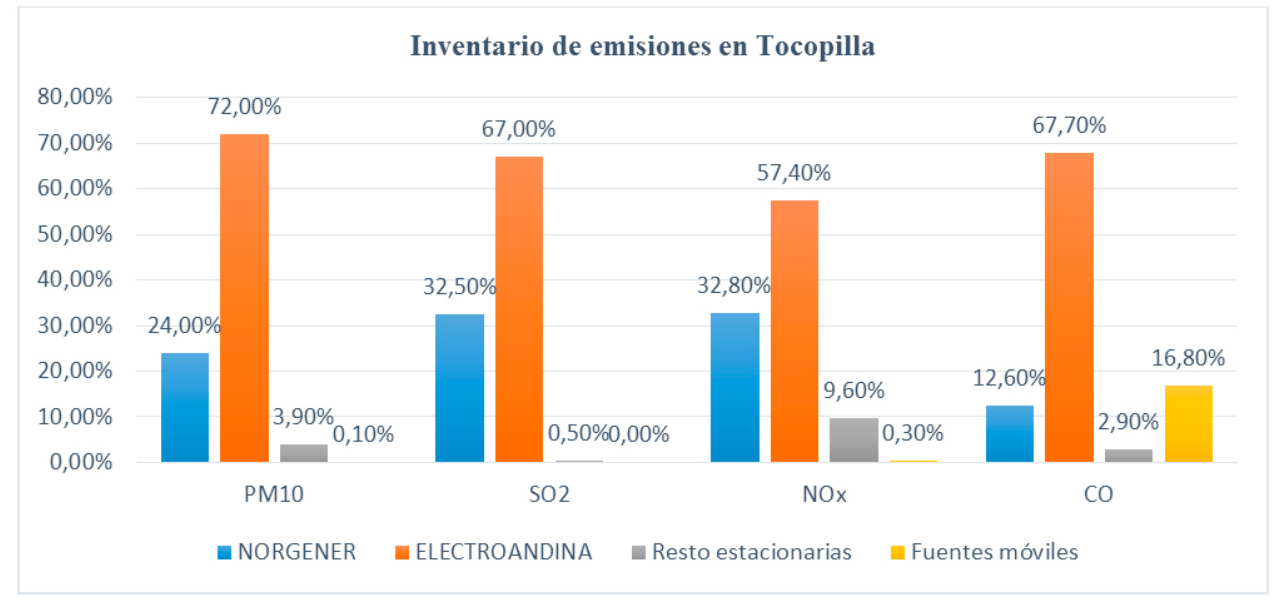

Figura 5. Inventario de emisiones en Tocopilla durante el año 2005. Fuente: AGPT, Informe DICTUC (2006).

Fuente: elaboración propia.

Los citados porcentajes de la Figura 2, llevados a la cifra de toneladas por año, contenía los siguientes datos (Tabla 1).

Tabla 1. Aporte de emisiones de toneladas por año de PM10, SO2, NOx y CO según su fuente de emanación.

\begin{tabular}{|l|c|c|c|c|}
\hline Aporte a las Emisiones (ton/año) & PM10 & SO2 & NOx & CO \\
\hline Norgener & 427.89 & $8,910.85$ & $5,799.10$ & 120.82 \\
\hline Electroandina & $1,286.52$ & $18,357.27$ & $10,146.06$ & 648.04 \\
\hline Resto estacionarias & 69.28 & 125.05 & $1,697.34$ & 27.66 \\
\hline Fuentes móviles & 2.13 & 2.93 & 47.35 & 161.36 \\
\hline TOTAL & $1,785.82$ & $27,396.10$ & $17,689.85$ & 957.88 \\
\hline
\end{tabular}

Fuente: AGPT, Informe DICTUC (2006). Esquema y adaptación: elaboración propia.

En ese escenario sombrío, las concentraciones ambientales de PM10 excedían ampliamente los estándares ambientales. Por ello, la Comisión Regional de Medio Ambiente en forma unánime concertó requerir la dictación de un Decreto Presidencial que determinara a Tocopilla como Zona Saturada de Contaminación. Fue entonces que la empresa Electroandina, el principal contaminante, apeló a que se debían conciliar "tanto los objetivos medioambientales como los económico-productivos en la zona, considerando asimismo el desafí que supone la generación de electricidad con las restricciones de gas natural proveniente de Argentina" (El Mercurio de Antofagasta, 10 de noviembre 2006). 
Una vez conocidos los resultados, la Intendenta de Antofagasta, la médica Marcela Hernando, propuso declarar a Tocopilla como Zona Saturada de Contaminación, considerando un radio de 87,6 kilómetros cuadrados (La Estrella de Antofagasta, 3 de noviembre 2006). El primer paso en dicha declaratoria fue la publicación de una resolución de la Comisión Regional del Medio Ambiente de Antofagasta (AGPT, Acuerdo No 0228/2006, acta No 15, 9 de noviembre de 2006). Esta resolución significó el análisis de los datos recogidos desde el año $2005^{10}$ (El Mercurio de Antofagasta, 10 de noviembre 2006). Al mismo tiempo, las empresas, en especial Electroandina, comenzó una campaña de desacreditación del informe de DICTUD, además de un intenso lobby político y de presión sobre los sindicatos de trabajadores para que Tocopilla no fuese declarada como Zona Saturada ${ }^{11}$.

El diario La Tercera indicó que la presidenta Michelle Bachelet Jeria contaba con un plazo estimado de 5 meses, para ratificar la declaración, y así generar un instrumento legal que permitiera crear un Plan de Descontaminación con la participación de un comité operativo, integrado por servicios públicos, fuentes contaminantes y organizaciones sociales de la comuna (La Tercera, 10 de noviembre 2006). No obstante, el tiempo comenzó a pasar sin noticias sobre el decreto que debía firmar el poder ejecutivo, se aducían problemas administrativos y "trabas legales" y una interpretación discrepante realizada por la Contraloría General de la República (El Mercurio de Antofagasta, 3 de agosto de 2007).

Fue recién el 22 de julio del año 2008 que, a través del Decreto No 74 del Ministerio Secretaría General de la Presidencia, se declaró a Tocopilla y su zona circundante como Zona Saturada por material particulado respirable (MP10), como concentración por cada 24 horas (AGPT, Decreto No 74 del Ministerio Secretaría General de la Presidencia, 22 de julio del año 2008).

Una vez declarada la Zona Saturada de Contaminación, Tocopilla adquirió una visibilización nacional, pero una visibilización negativa tanto a nivel mediático como de identidad cultural comunal. La polución era una nueva forma de patrimonio con una densa poética de la muerte y también era la manifestación de la aporía socioeconómica. Sin termoeléctrica, "no habría trabajo", pero sí, impactos seguros en la

10. Sin embargo, en la ventilación de todos los antecedentes surgidos en el proceso de evaluación, en La Prensa de Tocopilla se informó que una evaluación realizada en el año 2000, que también había arrojado antecedentes graves, respaldada con algunos datos duros, no fue considerada por las autoridades, terminando el informe completamente invisibilizado y oculto. "Desde el (año) 2000 contaminados: Así lo reveló acotación en la toma de razón de la Contraloría General de la República, mediciones recién fueron validadas el año 2005, dirigentes locales acusan responsabilidades politicas en el hecho" (La Prensa, Tocopilla, 29 de junio de 2007).

11. Sobre esto y otros detalles, ver blog del semanario El Polémico de Tocopilla (edición del 25 de abril de 2007). Recuperado de http://elpolemico.blogspot.com/2007/04/la-maniobra-de-electroandina-para.html. 
biología personal. Ya en 1999, el propio alcalde de Tocopilla, Aleksander Kurtovic, comentaba aquella "suerte de fatalismo", señalando a la revista Punto Final (Santiago) que "Tocopilla es una ciudad que, por su situación económica, no está en condiciones de exigir mucho. Si nos ponemos en las coloradas y rechazamos todo lo que es contaminación, a lo mejor las industrias que, de alguna manera son contaminantes, se van a cerrar y la gente se va a morir de hambre" (Revista Punto Final, No51912). De ese modo, el apocamiento y la timidez política, también cimentada por la desinformación, facilitarían aquellos adversos procesos sanitarios. En los hechos, a ojos de la autoridad, el hambre era estéticamente peor que la polución y la morbilidad y mortalidad derivada de la misma.

De aquella manera, la ciudad dio muestras de cómo el capitalismo se funda, se mantiene y se reproduce con la razón técnica y economicista fundándose en un modelo de acumulación por despojo, explotación y extractivismo, desigualdad sistémica, precariedad e individualización extrema de los problemas colectivos (Harvey, 2015). En ese sentido, la historia tocopillana estaba cruzada por ser una comunidad que sobrevivió con una carga tóxica de una necesidad sistémica, ante los requerimientos del llamado "desarrollo" y "modernización”, "cuando en realidad esta destrucción tiene el objeto de sostener los privilegios de gente que vive en otras zonas urbanas y que justifica o ignora la destrucción bajo la lógica de la razón técnica" (Emmelhainz, 2016, p. 2).

Si bien el 4 de octubre del año 2007 se publicó en el Diario Oficial el Decreto Supremo que declaraba a Tocopilla como territorio saturado, de modo siniestro y paradójico, un día después, la ciudad sufrió una concentrada lluvia de cenizas, evidenciándose nuevamente, las desprolijidades procedimentales. El diario La Prensa tituló: "El sector sur se tiñó de negro", indicando que la autoridad sanitaria de la región iniciaría un sumario en Electroandina por la contaminación generada y así establecer las causas y efectos de estas emisiones y definir qué sanciones se aplicarán a la empresa ${ }^{13}$.

12. Otras afirmaciones realizadas a Punto Final ( $\left.\mathrm{N}^{\circ} 519\right)$ tenían que ver con la corrupción de los medios de comunicación locales y de la política, la dirigente Urania Nikiforos señaló: "Lo que prima es el poder económico. Por ejemplo, Electroandina ayuda a financiar Radio Continente, que pertenece al diputado Waldo Mora (DC). Así, ¿qué se puede esperar de los políticos?”. Nikiforos, era una de las directoras del Comité de Defensa del Medio Ambiente en 1999. Recuperado de http://www. puntofinal.cl/519/tocopilla.htm.

13. Uno de los sectores más afectados fue la Población Alberto Hurtado. "Los pobladores manifestaron que por las noches siempre existe suspensión de cenizas desde las termoeléctricas, pero en forma de polvo y en menor cantidad, el cual barren cada mañana, pero esta vez fue distinto porque el hollín cayó prácticamente como una lluvia." (La Prensa, Tocopilla, 8 de noviembre 2007). 
El diario La Nación (Santiago) indicó el 17 de noviembre de 2007: "El DICTUC midió i47 mil toneladas! de gases y polvo en suspensión al año, según la especialista en Zonas Saturadas de CONAMA, Maritza Hadrícevic, dos toneladas por habitante".

\section{El impacto comunitario de la polución}

Es un consenso en los estudios epidemiológicos que, en las ciudades con Plantas de energía, se hallan las más altas tasas de hospitalización por enfermedades cardiovasculares, enfermedades respiratorias, cáncer y neumonía, siendo estadísticamente en los hombres los mayores impactos en términos de mortalidad y hospitalizaciones. Además, en esas mismas localidades, las tasas son significativamente altas en mortalidad cardiovascular, respiratoria, de cáncer y de pulmón y hospitalizaciones cardiovasculares, por problemas respiratorios, por cáncer y neumonía, superando, de ese modo, a las ciudades con papeleras y fundiciones (Ruiz-Rudolph et al., 2016).

Al recurrir a los datos del Instituto Nacional de Estadísticas, con base en los anuarios de defunciones regionales, desde el año 2000 hasta el año 2011, pudimos corroborar que las tasas de mortalidad en la Provincia de Tocopilla fueron coincidentemente en ascenso en el periodo en que las termoeléctricas usaron petcoke. Si bien el INE no explicita las causalidades de las muertes, el dato no puede ser soslayado porque el alza en las cifras de muertos en Tocopilla se ajusta y dialoga con la introducción de aquel combustible desde el año 2000 a través de Norgener y luego en Electroandina en el 2004 (Figura 6). Asimismo, se constata una fuerte diferenciación respecto a la realidad regional, en cuanto a las tasas de mortalidad en las Provincias de Antofagasta y Provincia de Calama en donde no se usaba petcoke.

En el análisis de la Figura 6, podemos ver que el año 2005 representa una punta, con una tasa de mortalidad de 7,4 por cada mil habitantes, es decir, un año después en que la termoeléctrica más grande, Electroandina (56\% del SING) ingresó definitivamente el petcoke. En el año 2005, la ciudad de Calama registró una tasa de mortalidad de 3,7 puntos; y Antofagasta registró una tasa de 4,5. Desde el mismo año 2005, la tasa comienza un leve descenso porque fue justamente el año en que las termoeléctricas estaban siendo evaluadas por DICTUC, lo cual implicó que disminuyeran la combustión de petcoke. Para el mismo año 2005, las estadísticas del Servicio de Salud de Antofagasta, indican que las enfermedades que generaron un mayor número de muertes fueron las enfermedades isquémicas al corazón y los tumores a los bronquios y a los pulmones.

Desde el año 1990 hasta el año 2000, la tasa de mortalidad en Tocopilla nunca superó el 6,0. Sin embargo, desde el 2004 hasta el año 2011, siempre estuvo más cerca del 7,0. 


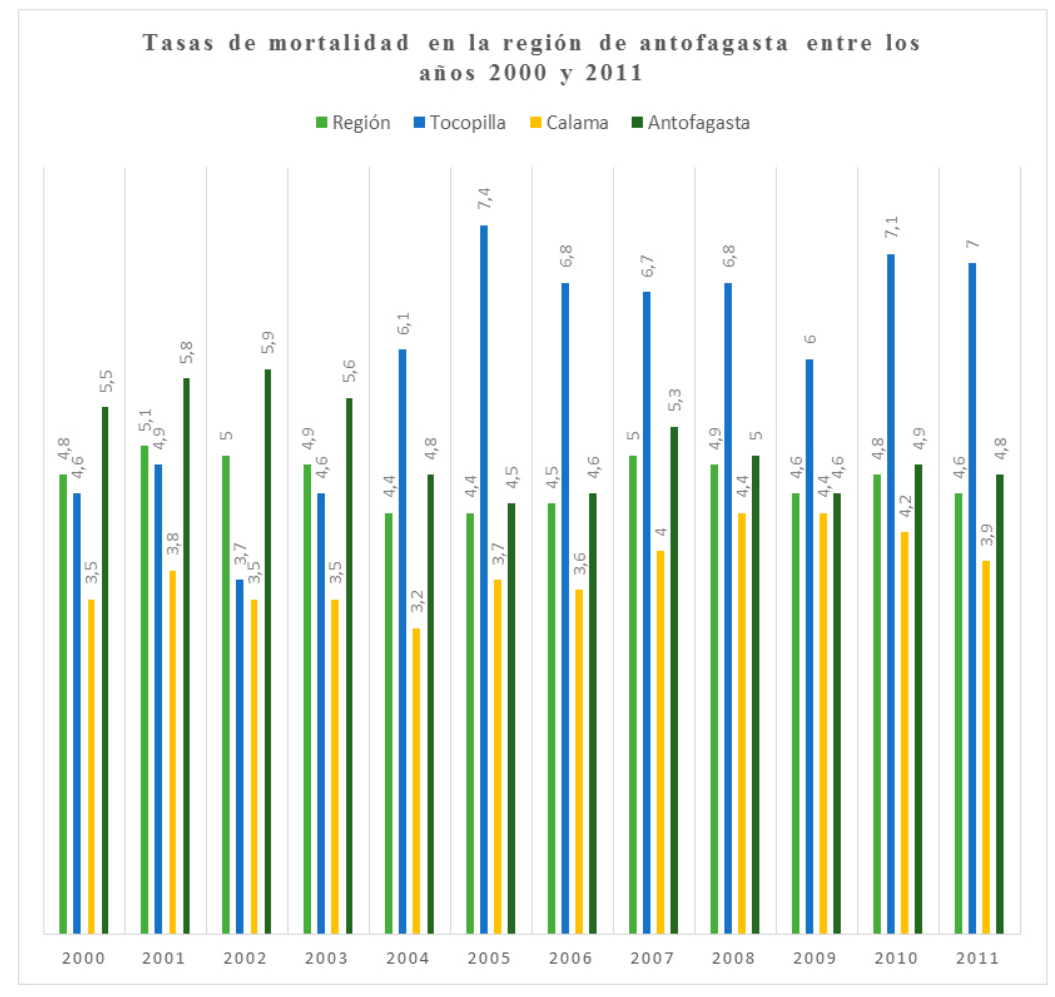

Figura 6. Tasas de mortalidad en la Región de Antofagasta por cada 1000 habitantes a través de sus tres provincias. Fuente: Instituto Nacional de Estadísticas de Chile. Fuente: elaboración propia.

Examinado la realidad por comuna en el año 2005 (Figura 7), advertimos que el puerto de Tocopilla alcanzó una tasa de 8,8 por cada 1000 habitantes, a saber que la realidad regional indicaba una tasa de mortalidad de 4,4. De aquella cifra, la tasa de 9,6 corresponde a hombres y 8,1 a mujeres. 


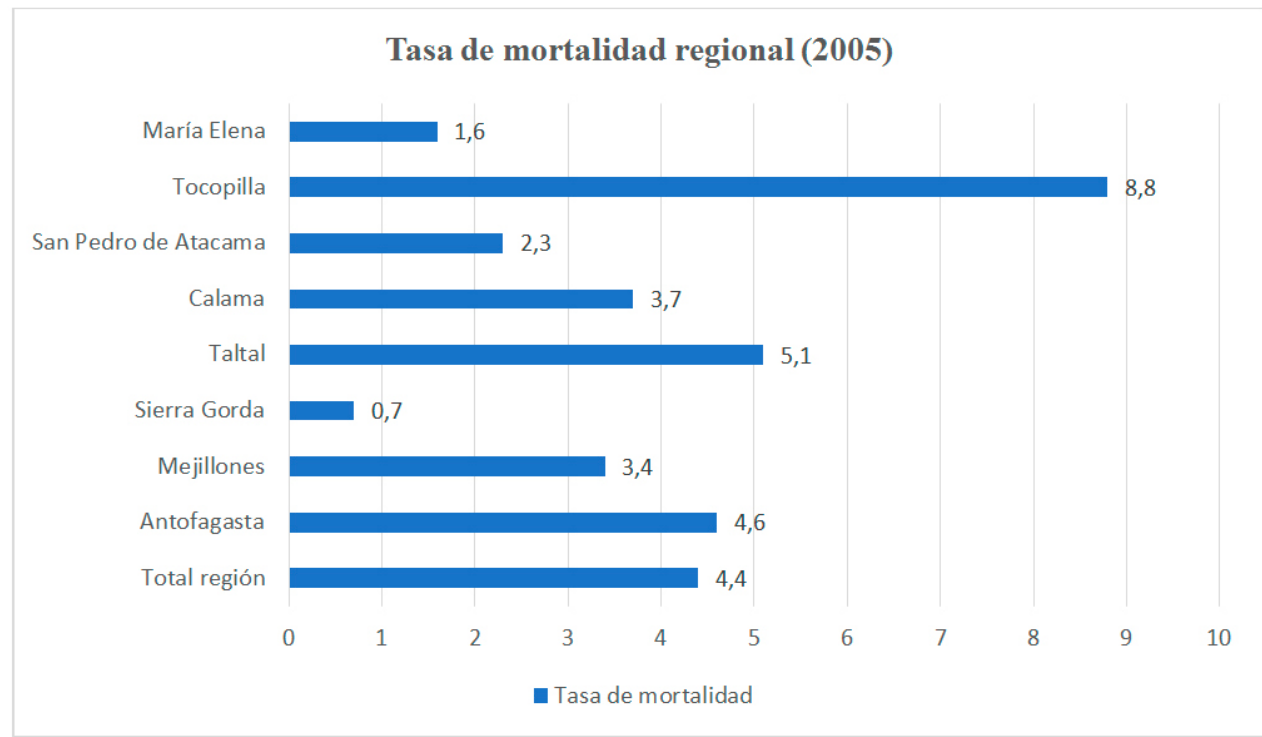

Figura 7. Tasas de mortalidad según las comunas de la Región de Antofagasta durante el año 2005. Fuente: Archivo Departamento de Estadísticas e Información de Salud, Chile (2005).

Fuente: elaboración propia.

Otro guarismo importante remitía a la tasa de mortalidad infantil en la Provincia de Tocopilla durante el año 2008, la cual fue de 14,2\%. El promedio nacional se situó en cerca de la mitad: $7,8 \%$.

Sin duda que el año 2010 también marcó un pináculo en la mortalidad general y en la mortalidad infantil, en este último caso, se duplicó a la media regional y nacional. (Tabla 2).

Tabla 2: Tasas de natalidad, mortalidad general e infantil año 2010.

\begin{tabular}{|l|c|c|}
\hline & Tasa de Natalidad & Tasa de Mortalidad Infantil \\
\hline Comuna de Tocopilla & 21,60 & 19,20 \\
\hline Región de Antofagasta & 17,40 & 8,70 \\
\hline País & 14,70 & 7,40 \\
\hline
\end{tabular}

Fuente: Archivo Departamento de Estadísticas e Información de Salud, 2011. Fuente: elaboración propia.

Dos años después de que el petcoke había sido autorizado, en el año 2002 se creó en Tocopilla una agrupación de vecinos voluntarios destinados a ayudar a los enfermos oncológicos: Agrupación de Ayuda al Enfermo de Cáncer (ADAEC). El diario La Prensa apuntó sobre esta congregación y los aquejados oncológicos: 
"Es un verdadero drama que lamentablemente sufren muchos grupos familiares del puerto. De ahí la importancia de ADAEC, puesto que con pocos recursos han conseguido aliviar en parte el sufrimiento de quienes padecen este mal. La enfermedad es costosa, los pacientes deben invertir grandes sumas de dinero para sus tratamientos" (La Prensa, 30 de abril de 2003).

Los enfermos de cáncer y una gran cantidad de dializados que vivían en Tocopilla, tenían que viajar a Antofagasta (distante a $185 \mathrm{~km}$ ) para largas sesiones de evaluación, tratamiento, quimioterapias y diálisis, porque el hospital tocopillano no contaba con especialistas ni oncólogos (La Tercera, 9 de agosto de 2013). Aquella situación generó un estallido social en agosto de 2013, provocándose fuertes protestas y bloqueos de carreteras que tuvieron como respuesta una fuerte represión policial (Galaz-Mandakovic, 2020, p. 69).

La agrupación ADAEC desde el año 2002 al 2006 había atendido a 210 enfermos de cáncer en Tocopilla, de los cuales 153 habían fallecido, "predominando (...) el cáncer al pulmón" (ADAEC, 2006, p. 22).

En el año 2011, la agrupación indicó que había ayudado a más de 400 personas. De ellos, en abril del 2011, solo 66 estaban vivos (La Prensa, 13 de abril, 2011). La directora de la organización filantrópica, Silvia Galleguillos, señaló en el año 2012: “hay casos de gente muy joven con melanomas gigantes ${ }^{14}$, niños con afecciones pulmonares. Casi todas las personas inscritas en nuestras carpetas están muertas" (Terram, 2012). Galleguillos agrega: "Tocopilla arrastra una cifra fantasma de gente que ha sacrifcado su salud por la minería, el gran negocio de Chile" (Terram 2012). En el año 2013, Silvia Galleguillos indicaba que la ciudad no había oncólogos: "asegura que los altos indices de casos de cáncer, así como de enfermedades respiratorias, tienen que ver con la presencia de las termoeléctricas y mineras...'Tenemos los diagnósticos. La gente se deriva a Antofagasta o Santiago"' (El Mostrador, 6 de agosto 2013).

Una investigación publicada en el año 2007 indicaba que las tasas de tumores malignos de tráquea, bronquios y pulmón, en la región de Antofagasta, en conjunto con la región de Atacama, poseían rangos significativamente mayores respecto a la región Metropolitana, del Maule, del Biobío y de la región de la Araucanía. En ese contexto, destacaban cinco comunas de la región de Antofagasta con tasas extremadamente al-

14. Según Héctor Fuenzalida, docente de la USACH y jefe del Departamento Oncodermatológico de Conac, indica que el aumento en la contaminación ambiental sumado a los altos niveles de radiación UV, son los factores que propician el cáncer melanoma. El investigador indica que las partículas y gases, "al entrar en contacto con la superficie de la piel, modifican los componentes reparativos de esta y aceleran la producción de radicales libres, que terminan por oxidarla. Esta piel debilitada es mucho más vulnerable a los daños genéticos que produce el efecto acumulativo de la radiación UV y eso se traduce en que el riesgo de desarrollar cáncer a la piel se triplica en estos lugares" (Terram, 2016). 
tas, éstas eran en forma creciente: María Elena, Taltal, Mejillones, Tocopilla y Antofagasta (Icaza et al., 2007, p. 1400). No obstante, el estudio enfatizó en la gravedad de los casos referidos a Tocopilla y Antofagasta, particularmente en el rango cronológico 1997 y 2004.

Sobre estos resultados concernientes a numerosas víctimas de tumores malignos de tráquea, bronquios y pulmón, el estudio de Icaza et al. (2007) indica que Chile no se encuentra dentro de los países con alta tasa de mortalidad por este tipo de cáncer en el mundo, sin embargo, en el análisis de los datos chilenos destacan dos comunas con tasas extremas altas, éstas son Tocopilla y Antofagasta. Indicándose que en estas comunas "dentro de los cánceres ocupacionales asociados a sustancias químicas, el de mayor frecuencia es el de pulmón" (Icaza et al., 2007, p. 1403). Sobre las afectaciones a los pulmones, el factor principal es la absorción de material particulado.

Otro estudio realizado centrado en el análisis del nivel de níquel urinario en niños residentes en ciudades cercanas a megafuentes, arrojó impactantes resultados. La concentración mediana de níquel en los escolares de Tocopilla fue de 3,9 $\mu \mathrm{g} / \mathrm{L}$. Estos resultados obtenidos en Tocopilla eran elevados comparados con la literatura internacional (Iglesias et al., 2008, p. 1041). Entonces, la exposición y cercanía a la termoeléctrica, expuso a los habitantes a la absorción de níquel debido a las altas concentraciones del metal en el agua de bebida y suelo, secundarias a su concentración en el aire, por efecto de la combustión de fósiles, especialmente el carbón y el petcoke.

Según los datos proporcionados por el Hospital Marcos Macuada de Tocopilla, la comuna registró el primer lugar regional en incidencia al cáncer de tráquea bronquios - pulmón con una tasa de 73,1 por 100.000 hombres en el quinquenio 2003-2007, seguido por el cáncer de próstata y piel no melanoma (Figura 8).

En el caso de las mujeres, los cánceres con mayores incidencias en la localidad que estudiamos para el quinquenio 2003-2007, fueron el cáncer de piel no melanoma, con una tasa de 63,8 por 100.000 mujeres. En segundo orden, aparece el cáncer de mama con 39,7 y en tercer lugar el cáncer a la tranque-bronquios-pulmón, con 22,4. Según el toxicólogo Andrei Tchernitchin (2010), las dioxinas del petcoke potencian la acción de otros compuestos carcinógenos, incluidos los estrógenos de la mujer causante de cáncer de mama. 


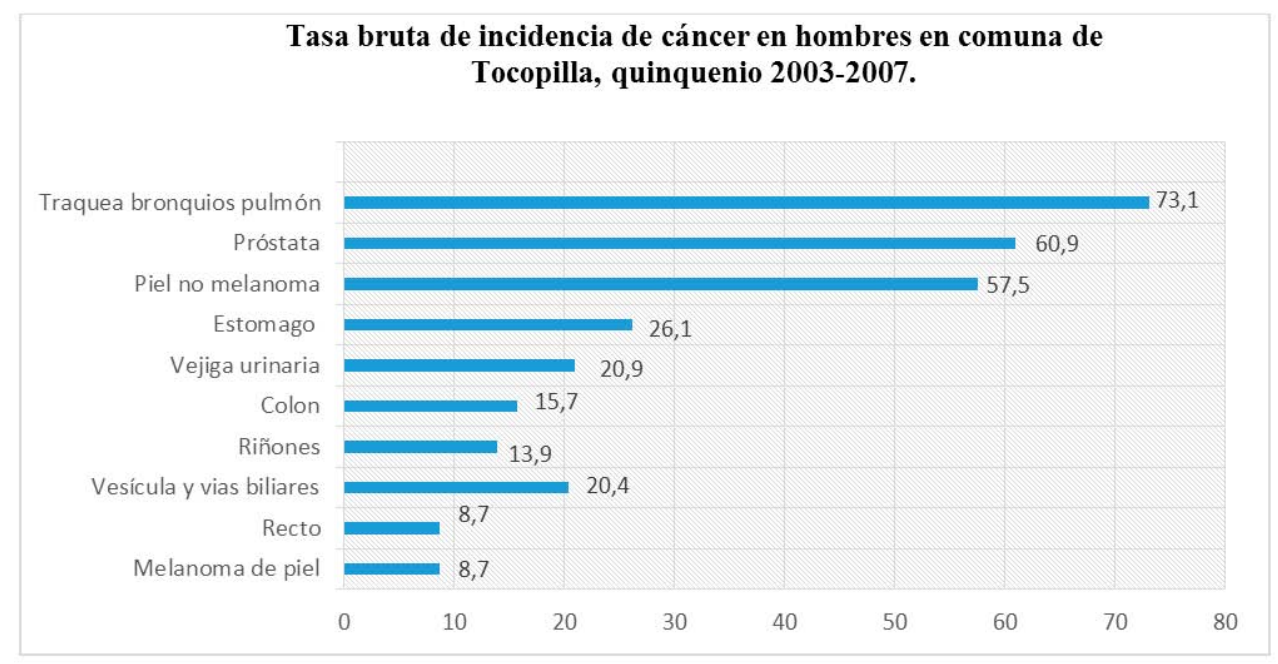

Figura 8. Tasa bruta de incidencia de cáncer en hombres en Tocopilla, quinquenio 2003-2007. Tasa x 100 mil hombres. Fuente: Archivo Hospital Marcos Macuada de Tocopilla, estadísticas basadas en el Registro Poblacional de Cáncer, Secretaría Regional Ministerial de Salud de Antofagasta.

Fuente: Elaboración propia.

\section{Plan de descontaminación}

La declaración de Zona Saturada de Contaminación en Tocopilla, trajo aparejada la dictación del "Plan de descontaminación atmosférico para la ciudad de Tocopilla y su zona circundante" (AGPT, Decreto № 70, 10 junio de 2010), publicado tardíamente el 12 de octubre de 2010 en el Diario Oficial a través del Ministerio Secretaría General de la Presidencia.

Un punto importante de este plan fue la consideración de otras fuentes contaminantes, las cuales complementaron mínimamente a las termoeléctricas en la emisión de altos niveles de material particulado, tales como LIPESED (procesamiento de minerales oxidados para producir cátodos de cobre) y la empresa SQM (ex SOQUIMICH), empresa que embarca nitratos y productos agroquímicos en Tocopilla. Otras fuentes correspondían a emanaciones pequeñas, tales como actividades que se realizan en la zona del puerto de Tocopilla, a las asadurías, a la molienda de algas, a las panaderías y a la empresa Corpesca S.A.

De acuerdo al inventario de emisiones, contenido en el estudio "Análisis técnico del plan de descontaminación por MP10 para Tocopilla y de las observaciones al anteproyecto" se cuantifica un total de 3.500 toneladas anuales de MP10 (Figura 9). 


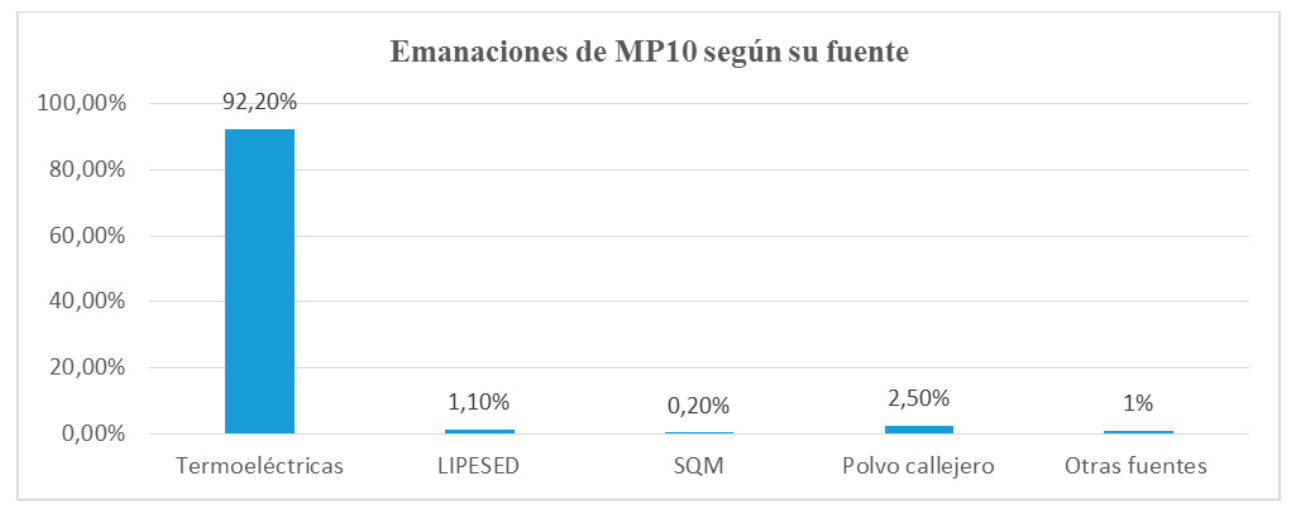

Figura 9. Porcentaje de emanaciones de MP10 según su fuente. Fuente: AGPT, Informe de Análisis técnico del plan de descontaminación por MP10 para Tocopilla y de las observaciones al anteproyecto, 2007.

Fuente: elaboración propia.

La proyección de las reducciones de contaminantes también quedó explícitamente establecida. (Tabla 3).

Tabla 3. Emanaciones de material particulado y su proyección de reducción.

\begin{tabular}{|l|c|c|c|c|c|}
\hline \multicolumn{1}{|c|}{$\begin{array}{c}\text { Actividad } \\
\text { emisora }\end{array}$} & $\begin{array}{c}\text { Emisiones } \\
\mathbf{2 0 0 7} \\
\text { toneladas } \\
\text { por año }\end{array}$ & $\begin{array}{c}\text { Aporte de } \\
\text { emisiones }\end{array}$ & $\begin{array}{c}\text { Emisión de } \\
\text { aplicación } \\
\text { de medidas } \\
\text { toneladas por } \\
\text { año }\end{array}$ & $\begin{array}{c}\text { Reducción } \\
\text { de emisiones } \\
\text { de toneladas } \\
\text { por año }\end{array}$ & $\begin{array}{c}\text { Aporte al } \\
\text { total de } \\
\text { emisiones }\end{array}$ \\
\hline Electroandina & 2.002 & $56,2 \%$ & $879 \mathrm{~T}$ por año & $\begin{array}{c}1.123 \mathrm{~T} \text { por } \\
\text { año }\end{array}$ & $54,3 \%$ \\
\hline Norgener & 1.386 & $38,9 \%$ & $469 \mathrm{~T}$ por año & $\begin{array}{c}917 \mathrm{~T} \text { por } \\
\text { año }\end{array}$ & $44,3 \%$ \\
\hline LIPESED & 40 & $1,1 \%$ & $34 \mathrm{~T}$ por año & $6 \mathrm{~T}$ por año & $0,3 \%$ \\
\hline SQM & 7 & $0,2 \%$ & $6 \mathrm{~T}$ por año & $1 \mathrm{~T}$ por año & $0,05 \%$ \\
\hline $\begin{array}{l}\text { Polvo } \\
\text { suspendido }\end{array}$ & 89 & $2,5 \%$ & $52 \mathrm{~T}$ por año & $\begin{array}{c}10 \mathrm{~T} \text { por año } \\
1 \%\end{array}$ \\
\hline Otras fuentes & 36 & $1,0 \%$ & $52 \mathrm{~T}$ por año & $11 \mathrm{~T}$ por año & $0,2 \%$ \\
\hline Total & 3.560 & $100 \%$ & $1492 \mathrm{~T}$ por año & $\begin{array}{c}2068 \mathrm{~T} \text { por } \\
\text { año }\end{array}$ & $100 \%$ \\
\hline
\end{tabular}

Nota: AGT, DS No 70, Ministerio Secretaría General de la Presidencia, 12 octubre 2010.

Fuente: elaboración propia. 
En lo concernientea las medidas de reducción de emisiones paralas termoeléctricas, el plan recomendaba cumplir en chimenea con el límite de emisión de 50 mg/Nm3: "el valor límite se evaluará en periodos de una hora y deberá cumplirse durante el 95\% de las horas de funcionamiento en estado en régimen, durante un año calendario. El $5 \%$ restante corresponde a etapas de encendido, apagado o probables fallas".

Sobre los niveles máximos de emisión de partículas, se ordenaba a Electroandina mantener los niveles de emisión de material particulado en 2.002 ton/año y Norgener S.A. en 1.386 ton/año, por un plazo de 3 años y 6 meses. Transcurrido el plazo indicado, las emisiones permitidas de material particulado debiesen bordear las 879 ton/año para Electroandina y 469 ton/año para Norgener.

Se ordenaba, igualmente, que en las chimeneas debiesen existir medidores de emisiones de partículas, particularmente de Dióxido de Azufre (SO2) y Óxidos de Nitrógeno (NOx), y el material particulado secundario junto al caudal, oxígeno y temperatura de los gases de salida.

Otra orden establecía que las termoeléctricas tenían la obligación de realizar un análisis de caracterización granulométrica del material particulado en el flujo de gases de las chimeneas de las Unidades a carbón usando impactadores de cascada. También se les exigió a las usinas que debían entregar a la Secretaría Regional Ministerial un informe anual sobre el cumplimiento de las medidas que establecía el plan de descontaminación (AGPT, Decreto Supremo № 70, Ministerio Secretaría General de la Presidencia, 12 octubre 2010, p. 9).

En caso de existir excesos de emanación, las empresas serían sometidas a un sumario para establecer las causas. Conllevando una serie de medidas de mitigación en la comunidad, por ejemplo, la suspensión de actividades físicas en las escuelas, suspensión de actividades comunitarias y productivas que significaran el levantamiento de polvo. La autoridad sanitaria de la región asumía la competencia de suspender las actividades que perjudicaran la salud de los tocopillanos. Al mismo tiempo, la Secretaría Regional Ministerial de Salud de Antofagasta, tendrían que informar a la comunidad sobre los episodios contaminantes a través de distintos dispositivos comunicacionales.

Finalmente, el proyecto de limpieza instruía a la Comisión Nacional de Medio Ambiente en conjunto con la Municipalidad de Tocopilla para que ejecutaran un plan de fortalecimiento de la gestión ambiental local.

Por su parte, la Secretaría Regional Ministerial de Salud de Antofagasta, quedaba comprometida a la realización de un informe anual sobre el cumplimiento de las materias de su competencia a CONAMA Región de Antofagasta o al organismo que la reemplace. El informe anual debía contener a lo menos los resultados del monitoreo de la calidad de aire, el inventario de emisiones atmosféricas para el año de evaluación, la comprobación del cumplimiento de los límites de emisión establecidos, 
como así también los medios de verificación del cumplimiento y evaluación del plan operacional para enfrentar episodios críticos. Adicionando el informe sobre la aplicación de sanciones.

Una de las primeras medidas implementadas por las termoeléctricas en este escenario de descontaminación, fue la instalación de pantallas ambientales de 18 metros de alto con malla galvanizada y doble malla Rachel instaladas en un perímetro lineal de 920 metros para cerrar la zona de almacenaje de carbón y atrapar el polvo arrastrado por el viento, el mejoramiento de los precipitadores de las Unidades de generación eléctrica, la adquisición de carbones con bajo contenido de cenizas para disminuir las emisiones de material particulado y finiquitar el uso del petcoke (La Prensa, 20 de noviembre 2008) ${ }^{15}$. Además, se instalaron los llamados Filtros de manga, que son los equipos que filtran los gases de salida de la caldera, reteniendo parcialmente el material particulado, dejando pasar a la chimenea solo los gases previamente filtrados; en pocas palabras, podemos indicar que es una versión a gran escala de una aspiradora, cuya bolsa de absorción, o en este caso las mangas, atrapan estas partículas del proceso, permitiendo mitigar parcialmente la afectación al ambiente ${ }^{16}$.

15. Según datos de la empresa, en la primera etapa de instalación, entre agosto y octubre de 2009, las "pantallas" lograron una disminución de hasta de $130 \mathrm{Ug} / \mathrm{m} 3 \mathrm{~N}$ de PM10 en uno de los puntos, equivalente a un $38 \%$. Además, la termoeléctrica Electroandina puso en marcha un proceso de instalación de filtros para reducir las emisiones. Según el consorcio, la inversión alcanzó un total de US \$170 millones en un periodo de tres años. El plan consistió en la instalación de filtros de mangas y otros sistemas para abatir emisiones de gases, proceso que llevó a renovar la tecnología de cerca de 800 MW de potencia instalada. La inversión, según la compañía, bordeó los US\$100 millones.

16. Simultáneamente a este proceso de descontaminación, las empresas Electroandina y Norgener constituyeron una política eficaz para la higiene de la imagen corporativa, financiando a una gran cantidad de grupos sociales, culturales, artísticos, deportivos, escolares, religiosos, vecinales, comunicacionales, incluso financiando campañas políticas y proyectos de la Gobernación Provincial y de la Municipalidad. Estos financiamientos fueron articulados por una sección llamada Departamento de Relaciones Comunitarias que, finalmente se constituyó en la institucionalización de cierto paternalismo e influencia política hacia la comunidad en aras de mejorar la proyección de la imagen y cooptar a los principales actores sociales y poder inhibirlos ante las complejas problemáticas ambientales. En ese marco de cooptación, se instituyó que las termoeléctrica Electroandina (hoy ENGIE) celebrara el Día del Periodista (11 de julio) y el Día de la Radio o del trabajador radial (21 de septiembre), generando de ese modo, una fuerte influencia al financiar una gran cantidad de programas radiales y auspicios en diarios. 


\section{Decreto para la permisividad de una mayor contaminación}

A saber del inicio de un proceso de descontaminación que buscó reducir la emanación de material particulado MP10 y MP2.5, en un plazo de siete años, durante los últimos meses del primer gobierno de Sebastián Piñera, se dictó el Decreto Supremo No 20 del 13 de diciembre del año 2013 (AGPT, Diario Oficial, 16 de diciembre 2013, pp. 3-7), el cual planteó la derogación del Decreto Supremo $\mathrm{N}^{\circ} 59$ de 1998, el mismo que establecía la Norma de Calidad Primaria para Material Particulado Respirable MP10, en especial de los valores que definen situaciones de emergencia, normativa que sustentó jurídicamente la declaración de Tocopilla como Zona Saturada de Contaminación. Dicho decreto de 1998 debía quedar derogado desde el 1 de enero de 2014. Estas medidas se tomaban a saber de los datos de mortalidad en Tocopilla que fueron publicados en el 2013, los cuales superaban la media regional y nacional. (Figura 10).

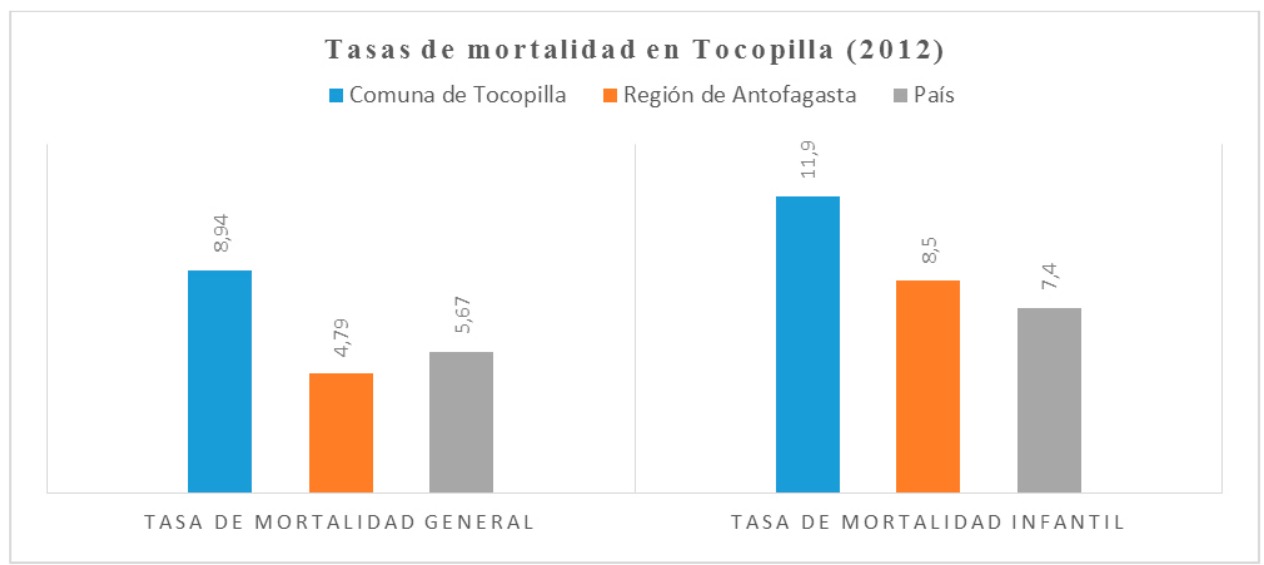

Figura 10. Tasas de mortalidad en Tocopilla correspondientes al año 2012. Fuente: Archivo Hospital Marcos Macuada.

Fuente: elaboración propia.

En decir de la Fundación Terram, según la regulación ambiental, una vez que se dicta una norma, ésta debe ser sometida a un proceso de revisión y actualización cada 5 años, "Sin embargo, en vez de hacer esta evaluación y poner una normativa más exigente, se derogó la norma anual con procedimientos bastante dudosos" (Terram, 2015). De esta forma, la propuesta del gobierno de Sebastián Piñera, alteraba sustancialmente el Plan de Descontaminación en Tocopilla con una serie de ambigüedades que favorecían evidentemente a las termoeléctricas, no alcanzándose a cubrir los siete años del citado plan, generando una fuerte incertidumbre en la comunidad. 
A solo tres días después de firmado el Decreto Supremo, y en el mismo día en que se publicaba en el Diario Oficial de Chile, el presidente Sebastián Piñera participaba en la llamada "Cumbre Energética" (La Tercera, 18 de diciembre de 2013), actividad realizada en el Palacio de la Moneda con "representantes de las empresas generadoras de electricidad, casi en un 100\% empresas extranjeras" (Cuenca, 2013).

La dictación del Decreto Supremo N 20 de 2013 motivó a que la municipalidad de Tocopilla (durante la gestión del alcalde Fernando San Román Bascuñán, 2012-2016) presentara una reclamación ante el Tribunal Ambiental de Santiago ${ }^{17}$. Los argumentos se orientaban a que el límite de $150 \mu \mathrm{g} / \mathrm{m} 3 \mathrm{~N}$ como norma primaria de calidad del aire para MP10 diario mantenida en el Decreto № 20, no concordaba con la realidad científica, siendo este decreto extremadamente permisivo lo que perjudicaría gravemente la salud de los habitantes (OLCA, 2014).

El municipio tocopillano consideró que el decreto derogaba la norma de calidad anual de MP10 de 50 microgramos por metro cúbico normal ( $50 \mu \mathrm{g} / \mathrm{m} 3 \mathrm{~N})$ como concentración anual, dejando solamente la concentración de $150 \mu \mathrm{g} / \mathrm{m} 3$ para el período de 24 horas (La Estrella de Tocopilla, 31 de enero 2014).

Tras su análisis el Tribunal Ambiental resolvió anular totalmente el citado decreto del Poder Ejecutivo de diciembre de 2013, en razón de carecer de los fundamentos exigidos por ley y por contener una serie de vicios de procedimiento, revelando una falta de fundamentación y una ambigüedad informativa que significaría un fuerte impacto en la población. Finalmente, se dejó sin efecto por nulidad consecuencial, a través de la Resolución Exenta $N^{\circ} 57$ de 31 de diciembre de 2013 del Ministerio del Medio Ambiente, que modificaba el Decreto $\mathrm{N}^{\circ} 20$ de 2013, publicada el 21 de febrero de 2014.

No obstante, una vez celebrado este triunfo judicial, llegó a Tocopilla la noticia de la intervención del Consejo de Defensa del Estado, organismo que interpuso un recurso de casación en enero de 2014 ante la Corte Suprema para dejar sin efecto este fallo. Lamentablemente para los tocopillanos, la búsqueda de la nulidad del Decreto Supremo del Gobierno de Sebastián Piñera, quedó paralizado, y de esta forma la norma permisiva sería puesta en práctica (La Estrella de Tocopilla, 13 de enero 2015).

Sin embargo, la Corte Suprema rechazó la casación interpuesta por el Consejo de Defensa del Estado a nombre del Ministerio de Medioambiente (dirigido por María Ignacia Benítez) y confirmó el fallo del Tribunal Ambiental que anuló modificación a

17. Al municipio de Tocopilla se sumaron otras localidades que también serían afectadas por la decisión el presidente Sebastián Piñera, tales como la Municipalidad de Puchuncaví, la Municipalidad de Huasco, Vecinos de La Greda, Quintero, Cerro Navia, La Florida, Estación Central y Las Condes, adicionándose los particulares Fernando Dougnac Rodríguez, Diego Lillo Goffreri y Gabriela Burdiles Perucci. Por su parte, los municipios afectados crearon la Unión de Municipios en Zonas de Sacrificio. 
norma de material particulado MP10 (Archivo Tribunal Ambiental de Chile (ATAC), Rol No 1.119-2015). De ese modo, los planes permisivos iniciados bajo el gobierno de Piñera quedaron anulados.

Mientras transcurrían estos procesos judiciales, en mayo del 2014 la municipalidad de Tocopilla denunció en los medios que la Superintendencia de Medio Ambiente (SMA) había detectado que la termoeléctrica Norgener se había sobrepasado en la emisión de material particulado. En ese sentido, a través de una resolución fechada el 5 de mayo, formuló cargos contra la termoeléctrica por no realizar a tiempo el proceso de instalación y certificación de monitoreo de sus emisiones contaminantes (La Estrella de Tocopilla, 27 de mayo 2014).

El Municipio tocopillano señaló que, aunque Norgener debía obtener su certificación el 23 de junio 2013, los análisis realizados a fines de ese año e inicios de 2014 por la Superintendencia de Medio Ambiente, indicaron que la termoeléctrica no cumplió con esta obligación, por lo que la Superintendencia rechazó el informe de resultados que la empresa entregó respecto a su proceso de instalación y certificación de monitoreo, contenidos en una serie de ensayos referidos a diversos aspectos medibles (La Estrella de Tocopilla, 27 de mayo 2014). El alcalde Fernando San Román señaló: "Hacemos un llamado a esta empresa norteamericana a respetar las leyes chilenas y a respetar a la comunidad" (Diario de Antofagasta, 27 de mayo 2014).

Con estas escenas propias de un régimen de indolencia industrial y política que trajo aparejado la insensibilidad social por parte de los consorcios eléctricos, desde Santiago se reafirmaba la condición de Tocopilla como zona de sacrificio ambiental, remitiéndonos a la colonización ambiental y la primacía de los intereses corporativos que cooptaron los poderes del Estado, donde la economía era el eje de acción por sobre la salud de la población.

En el año 2015, la Región de Antofagasta se visibilizaba como región de relevancia económica al aportar con $45 \%$ del PIB minero del país, y por concentrar entre el $25 \%$ al 30\% del total de exportación del país. El sector de la minería representaba el 95\% de las exportaciones regionales (Gobierno Regional de Antofagasta, 2015). No obstante, hacia el año 2016, a saber de la desaparición del petcoke, pero no así sus huellas en las enfermedades, la comuna de Tocopilla presentaba un riesgo de morir $22 \%$ mayor, respecto a la tasa de mortalidad general del país. Considerando la mortalidad por tumores malignos de tráquea, bronquios y pulmón, se observaba un riesgo significativamente superior en la comuna de Tocopilla, con un valor de 2,7 veces más de riesgo respecto al resto de Chile (Cortés et al., 2019). De ese modo, la minería y la generación de energía eléctrica conlleva una necroeconomía articulada en un espacio periférico para la política, pero central para la energización de la explotación del cobre. 


\section{Conclusión}

Con los antecedentes que hemos entregado, podemos caracterizar el caso tocopillano como un aciago ejemplo de contradicción del capitalismo (Harvey, 2015), en cuanto a que existen dos fuerzas aparentemente opuestas y simultaneas que se presentan en una actividad extractiva: generar electricidad para extraer minerales y así extender la vida de la sociedad, pero en su paradoja, para que dicho objetivo sea alcanzando, algunos deben ser sacrificados. Es allí donde la institucionalidad nacional es subsumida e instrumentalizada, siendo la población local la que asumió los costos sanitarios, deviniendo un territorio distópico carente de la llamada justicia ambiental (Infante, 2016). Entonces, estas Zonas de Sacrificio develan también que el problema de la contaminación dialoga y profundiza los patrones de desigualdad social y de asimetría económica, porque son las comunidades de menores ingresos las que soportan y contienen los efectos negativos del crecimiento económico (Carmona y Jaimes 2015; Emmelhainz, 2016; Klein, 2015).

En ese marco, la necroeconomía de la generación de electricidad para la gran minería que se densificó con la introducción del petcoke, es posible comprender que el ciclo económico se inicia mucho antes, se inicia cuando se dispone como recurso explotable a los suelos, el aire, el mar y también las corporalidades, las cuales se transforman y se introducen forzosamente en el ciclo productivo, pero que por los cuales nadie responde. Asimismo, la necroeconomía de la generación de energía eléctrica para la gran minería del cobre, nos remite al adelgazamiento estatal que se traduce en las alteraciones metabólicas del paisaje y de los habitantes por efecto de la permisividad ante acciones contaminantes que estructuran una crisis, sobre las cuales se actúa tardíamente a través de algunas declaratorias y febles planes de descontaminación. También, podemos ver que la plataforma del Estado es manipulada con fuertes conflictos de intereses, tal como lo representó el presidente Sebastián Piñera que, en los hechos, profundizaron el cauce necropolítico y necroeconómico a través de la vulneración hacia la población, la cual fue vista siempre como recipiente del material particulado generado por la combustión del petcoke y los carbones bituminosos.

Por aquella razón, tal como afirma Achille Mbembe, el capitalismo y sus adláteres expone a estas poblaciones consideradas como "desechables" y residuales a todo tipo de peligros. La necropolítica sería, entonces, la transcripción ideológica de esta modalidad de violencia que ejerce el capitalismo minero contemporáneo en el desierto de Atacama.

Entonces, aquel adelgazamiento, corrupción, anacronía y lentitud del Estado del cual hablamos en cuanto al déficit de la función protectora y como garante de la vida, remite también a lo Mbembe llama el derrumbe ante el "gobierno privado indirecto" (Mbembe, 2006), que sería aquel movimiento de las elites económicas, que buscan en última instancia, disipar la política de los Estados y convertirlos en aparatos buro- 
cráticos subalternos al capital, enlazándose el poder económico, la violencia química y la acumulación financiera derivada de los procesos anteriores. Así surgió la separación radical entre los que deben vivir y a quienes se les deja morir (Foucault, 2007).

Es posible ver este proceso necroeconómico como una captura de carácter colonial que ejercen ciertos consorcios, superando en potencia e influencia al propio Estado, surgiendo verdaderos Estados de excepción químicos, densificándose la violencia lenta, la misma que ocurre de modo gradual, fuera de la visión, que es retrasada, de largo aliento y que es incremental (Nixon, 2011), surgiendo de ello un modo de desechamiento (Voyles, 2015) que en muchos casos del norte de Chile ya está normalizado. Así, el despojo colonialista en nombre del "crecimiento", fue mermando la vida de las poblaciones locales a través de un nuevo régimen químico, derivando un modo de intensificación biopolítica de la vulneración, de la apropiación de los cuerpos y la gestión necrótica al servicio de las energías del mercado.

\section{Referencias}

ADAEC (2006). ¿Qué es ADAEC? Revista del Centro Hogar de Tocopilla en Antofagasta, s/n. pp. 22-23.

Andrews, Anthony y Richard Lattanzio (2013). Petroleum Coke: Industry and Environmental Issues. En CRS Report Prepared for Members and Committees of Congress. Washington, DC: Congressional Research Service.

ATSDR (2003). Toxicological Profile for Vanadium. Agency for Toxic Substances and Disease Registry. Recuperado de https://wwwn.cdc.gov/TSP/ToxProfiles/ToxProfiles.aspx?id=276\&tid=50.

Carmona, Javiera y Melisa Jaimes (2015). Desigualdad ambiental y desigualdad comunicacional: Las portadas de El Mercurio de Valparaíso sobre el derrame de petróleo en la bahía de Quintero. Cuadernos info, 36, 71-87. Doi: http://ojs.uc.cl/ index.php/cdi/article/view/23703.

Cortés, Sandra, Karla Yohannenssen, Lidya Tellerías y Ericka Ahumada (2019). Exposición a contaminantes provenientes de termoeléctricas a carbón y salud infantil: ¿Cuál es la evidencia internacional y nacional? Revista Chilena de Pediatría, 90(1): 102-114. Recuperado de https://www.revistachilenadepediatria.cl/index. $\mathrm{php} / \mathrm{rchped} /$ article/view/748.

Costas, Antón (2014) Exceso de capitalismo concesional y rentista. España: El País. Recuperado de https://elpais.com/economia/2014/02/21/actualidad/1392982265_238560.html. 
Cuenca, Lucio (2013). Piñera regala a empresas eléctricas nuestra salud envuelta en impunidad. Santiago: Observatorio Latinoamericano de Conflictos Ambientales. Recuperado en http://www.g80.cl/noticias/columna_completa.php?varid=19077.

DICTUC (2006). Análisis de la Calidad del Aire para MP-10 en Tocopilla. Santiago: División Ingeniería Química y Bioprocesos, División Ingeniería de Transporte, Pontificia Universidad Católica de Chile. Recuperado de http://www.dim.uchile. cl/ lgallard/VOCALS/MONITORING/Informe_Final_Calidad_AIRE_PM10_ TOCOPILLA.pdf.

Emmelhainz, Irmgard (2016). Antropoceno y razón técnica: destrucción modernista y acción política. Campo de relámpagos y Artium. Centro-Museo Vasco de Arte Contemporáneo de Vitoria-Gasteiz. Recuperado de http://campoderelampagos. org/critica-y-reviews/4/6/2016.

Fernández-Savater, Amador (2016). Achille Mbembe: Cuando el poder brutaliza el cuerpo, la resistencia asume una forma visceral. España: El Diario.es, Recuperado de https://www.eldiario.es/interferencias/Achille-Mbembe-brutaliza-resistenciavisceral_6_527807255.html.

Foucault, Michel (2007). Seguridad, territorio, población: Curso en el Collège de France. (1977-1978). Argentina: Fondo de Cultura Económica.

Galaz-Mandakovic, Damir (2017). Inclusions, transformations et asymétries du capitalisme minier sur la cote d'Atacama: les dérives de la production thermoélectrique a Tocopilla (Chili) 1914-2015. (Thèse de doctorat Histoire, Université Rennes 2, France). Recuperado de http://www.theses.fr/2017REN20069.

Galaz-Mandakovic, Damir (2018). Desechos, aluviones y racismo de Estado. El caso de la población Pacífico Norte de Tocopilla (Chile) 2009-2015. Revista Rumbos TS. (17): 97-130. Recuperado de http://revistafacso.ucentral.cl/index.php/rumbos/article/view/20.

Galaz-Mandakovic, Damir (2019). Movimientos, tensiones y luces. Historias tocopillanas. Tocopilla: Ediciones Bahía Algodonales.

Galaz-Mandakovic, Damir (2020). Memoria, adversidades y conflictos en el acontecer de la asimetría y el rezago en Tocopilla (Chile, 1915-2013). Revista de la Academia, (30): 43-83. Doi: https://doi.org/10.25074/0196318.0.1695.

Gamboa, Ricardo y Carlos Huneeus (2007). La interconexión gasífera Chile-Argentina: objetivos y actores. Estudios Internacionales, 40 (157): 83-116.

Gobierno Regional de Antofagasta (2015). Región de Antofagasta / Aspectos económicos. Antofagasta: Recuperado de https://www.goreantofagasta.cl/aspectos-economicos/goreantofagasta/2016-09-26/095739.html. 
Harvey, David (2015). Diecisiete contradicciones del capital y el fin del neoliberalismo. Quito: Editorial IAEN.

Hormazabal, Nina, Sandro Maino, Magdalena Vergara y Matías Vergara (2019). Habitar en una zona de sacrificio: Análisis multiescalar de la comuna de Puchuncaví. Revista Hábitat Sustentable, 9(29): 6-15. Doi: https://doi.org/10.22320/07190700 .2019.09.02.01.

Icaza, María Gloria, Loreto Núñez, Francisco Torres, Nora Díaz y David Varela (2007). Distribución geográfica de mortalidad por tumores malignos de estómago, tráquea, bronquios y pulmón, Chile 1997-2004. Revista médica de Chile, 135(11): 1397-1405. Doi: http://dx.doi.org/10.4067/S0034-98872007001100005.

Iglesias, Verónica, Soledad Burgos, Nella Marchetti, Claudio Silva y Paulina Pino (2008). Nivel de níquel urinario en niños residentes en ciudades cercanas a megafuentes. Revista médica de Chile, 136 (8): 1039-1046. Doi: http://dx.doi.org/10.4067/ S0034-98872008000800013.

Infante, Paloma (2016). (In)justicia ambiental en Chile y principales mecanismos para mitigar la inequidad: planificación territorial y derechos de comunidades vulnerables. Revista de Derecho Ambiental, 6, 143-163. Recuperado de https://revistaderechoambiental.uchile.cl/index.php/RDA/article/view/43319/45305.

Instituto Nacional de Estadísticas (2002). XVII Censo de Población y VI de Vivienda 2002. Santiago de Chile: INE.

Katz, Ricardo (2001). Efectos ambientales de la sustitución de carbón por petcoke en la generación eléctrica y procesos industriales. Revista Ambiente y Desarrollo, 17, 22-9.

Klein, Naomi (2015). Esto lo cambia todo: el capitalismo contra el clima. Madrid: Paidós Ibérica.

Mbembe, Achille (2006). Necropolitica. Sobre el gobierno privado indirecto. España: Ediciones Melusina.

Moguillansky, Graciela (1997). La gestión privada y la inversión en el sector eléctrico chileno. Santiago: Serie Reformas económicas, Cepal. Recuperado de https://repositorio.cepal.org/handle/11362/7378.

Montoya-Aguilar, Carlos (2009). Cáncer en la región de Antofagasta, con especial referencia al cáncer vesical y al cáncer pulmonar. Cuadernos Médicos Sociales, 47 (3):162-175. Recuperado de https://cutt.ly/otxDbgN.

Murphy, Michelle (2008). Chemical Regimes of Living. Environmental History, 13(4): 695-703. Recuperado de https://www.jstor.org/stable/25473297?seq=1. 
Nixon, Rob (2011). Slow Violence and the Environmentalism of the Poor. Cambridge: Harvard University Press.

OLCA (2014). Municipio de Tocopilla interpone recurso de reclamación por cambio a norma de emisiones contaminantes. Santiago: Observatorio Latinoamericano de Conflictos Ambientales. Recuperado de http://olca.cl/articulo/nota. php?id=104066.

Papava, Vladimer (2005). Necroeconomics: the political economy of post-Communist capitalism. New York: iUniverse.

Ruiz-Rudolph, Pablo, Nelson Arias, Sandra Pardo, Marianne Meyer, Stephanie Mesías, Claudio Galleguillos, Irene Schiattino y Luis Gutiérrez (2016). Impact of large industrial emission sources on mortality and morbidity in Chile: A small-areas study. Environ Int., 130(93): 92-93. Doi: https://doi.org/10.1016/j.envint.2016.03.036.

Santos, Aldo y Rogerio Silva (2008). Análisis del Consumo de Coque de Petróleo en Algunos Sectores Industriales. Información tecnológica, 19(2): 93-101. Recuperado de http://dx.doi.org/10.4067/S0718-07642008000200011.

Tchernitchin, Andrei (2010). Efecto de las centrales termoeléctricas sobre la salud, biodiversidad y desarrollo sustentable. Caldera, Chile: Colegio Médico de Chile (PPT).

Terram (2012). Mujeres de la ciudad en penumbra. Fundación Terram. Recuperado de https://www.terram.cl/2012/06/mujeres_de_la_ciudad_en_penumbra/.

Terram (2015). La vergüenza del MP10. Fundación Terram. Recuperado de https:// www.terram.cl/2015/01/la-verguenza-del-mp10/.

Terram (2016). Confirman que riesgo de cáncer a la piel se acentúa con la contaminación. Fundación Terram. Recuperado de https://www.terram.cl/2016/12/confirman-que-riesgo-de-cancer-a-la-piel-se-acentua-con-la-contaminacion/.

Toledo, Víctor (2013). El metabolismo social: una nueva teoría socioecológica. Relaciones. Estudios de historia y sociedad, 34(136): 41-71. Recuperado de http://www. scielo.org.mx/scielo.php?script=sci_arttext\&pid=S0185-39292013000400004.

Vidal, Gladys (2005). Gestión integral de cenizas generadas por la utilización del Coke de Petróleo. Concepción: Centro de Ciencias Ambientales EULA-Chile, Universidad de Concepción. Recuperado de http://www.eula.cl/giba/wp-content/uploads/2017/09/gestion-integral-de-las-cenizas-generadas-por-la-utilizacion-delcoke-de-petroleo.pdf.

Voyles, Tracy (2015). Wastelanding: Legacies of Uranium Mining in Navajo Country. Minneapolis: University of Minnesota Press. Recuperado de https://www.upress. umn.edu/book-division/books/wastelanding. 


\section{Archivos}

ABCN: Archivo y Biblioteca del Congreso Nacional de Chile.

ADEIS: Archivo del Departamento de Estadísticas e Información de Salud, Chile.

AGPT: Archivo de la Gobernación Provincial de Tocopilla.

AHMT: Archivo Hospital Marcos Macuada de Tocopilla.

ATAC: Archivo Tribunal Ambiental de Chile.

\section{Fuentes hemerográficas}

Diario de Cooperativa, Santiago.

Diario de Antofagasta, Antofagasta.

Diario El Mercurio, Antofagasta.

Diario El Mercurio, Santiago.

Diario El Mostrador, Santiago.

Diario La Estrella de Antofagasta, Antofagasta.

Diario La Estrella, Tocopilla.

Diario La Nación, Santiago.

Diario La Prensa, Tocopilla.

Diario La Tercera, Santiago.

Diario Oficial de Chile, Santiago.

Semanario El Polémico, Tocopilla.

Revista Punto Final, Santiago.

\section{Sobre el autor:}

Damir Galaz-Mandakovic Fernández es Profesor de Historia y Geografía por la Universidad de Tarapacá (2008), Magíster en Ciencias Sociales por la Universidad de Antofagasta (2013), Magíster y Doctor en Antropología por la Universidad Católica del Norte (2017) y Docteur en Histoire por Université Rennes 2 (2017). Ha desarrollado sus investigaciones sobre la historia de la minería en el desierto de Atacama y en el suroeste de Bolivia durante el siglo XX, con énfasis en los procesos tecnológicos y sus derivaciones urbanas, migratorias, biopolíticas, sociales, arquitectónicas y ambientales. Dirige el proyecto Fondecyt 11180932. Correo Electrónico: damirgalaz@gmail. com. iD https://orcid.org/0000-0003-0312-6672 


\title{
CUHSO
}

Fundada en 1984, la revista CUHSO es una de las publicaciones periódicas más antiguas en ciencias sociales y humanidades del sur de Chile. Con una periodicidad semestral, recibe todo el año trabajos inéditos de las distintas disciplinas de las ciencias sociales y las humanidades especializadas en el estudio y comprensión de la diversidad sociocultural, especialmente de las sociedades latinoamericanas y sus tensiones producto de la herencia colonial, la modernidad y la globalización. En este sentido, la revista valora tanto el rigor como la pluralidad teórica, epistemológica y metodológica de los trabajos.

\author{
EDITOR \\ Matthias Gloël \\ CoORdinadora EDITORIAL \\ Claudia Campos Letelier \\ Corrector de ESTILO Y DiSEÑAdor \\ Ediciones Silsag \\ TRADUCTOR, CORRECTOR LENGUA INGLESA \\ Aurora Sambolin Santiago \\ SITIO WEB \\ cuhso.uct.cl \\ E-MAIL \\ cuhso@uct.cl
}

LICENCIA DE ESTE ARTÍCULO

Creative Commons Atribución Compartir Igual 4.0 Internacional 